ARTICLE

https://doi.org/10.1038/s41467-019-13603-6

\title{
B cell-intrinsic epigenetic modulation of antibody responses by dietary fiber-derived short-chain fatty acids
}

Helia N. Sanchez ${ }^{1,4}$, Justin B. Moroney ${ }^{1,4}$, Huoqun Gan ${ }^{1,2}$, Tian Shen², , John L. Im¹, Tianbao Li ${ }^{3}$, Julia R. Taylor (1) ${ }^{1}$, Hong Zan (1) ${ }^{1 \star} \&$ Paolo Casali id ${ }^{1 \star}$

Short-chain fatty acids (SCFAs) butyrate and propionate are metabolites from dietary fiber's fermentation by gut microbiota that can affect differentiation or functions of $T$ cells, macrophages and dendritic cells. We show here that at low doses these SCFAs directly impact B cell intrinsic functions to moderately enhance class-switch DNA recombination (CSR), while decreasing at higher doses over a broad physiological range, AID and Blimp1 expression, CSR, somatic hypermutation and plasma cell differentiation. In human and mouse B cells, butyrate and propionate decrease B cell Aicda and $\operatorname{Prdm} 1$ by upregulating select miRNAs that target Aicda and Prdm1 mRNA-3'UTRs through inhibition of histone deacetylation (HDAC) of those miRNA host genes. By acting as HDAC inhibitors, not as energy substrates or through GPRengagement signaling in these B cell-intrinsic processes, these SCFAs impair intestinal and systemic T-dependent and T-independent antibody responses. Their epigenetic impact on $B$ cells extends to inhibition of autoantibody production and autoimmunity in mouse lupus models.

\footnotetext{
${ }^{1}$ Department of Microbiology, Immunology \& Molecular Genetics, University of Texas Long School of Medicine, UT Health Science Center, San Antonio, TX 78229, USA. ${ }^{2}$ Xiangya School of Medicine, Central South University, Changsha, Hunan 410011, China. ${ }^{3}$ Department of Molecular Medicine, University of Texas Long School of Medicine, UT Health Science Center, San Antonio, TX 78229, USA. ${ }^{4}$ These authors contributed equally: Helia N. Sanchez, Justin B. Moroney. *email: zan@uthscsa.edu; pcasali@uthscsa.edu
} 
E pigenetic mechanisms, as influenced by nutritional and environmental factors, including dietary fibers and gut microbiota, maintain and fine-tune immune responses and homeostasis ${ }^{1-4}$. These are critical to health and disease, as they restrict microbial pathogens while restraining immune overactivity. Indeed, immune cells epigenetic dysregulation can result in aberrant immune responses, as in allergy and autoimmunity $^{5-8}$. Gut microbiota, particularly Clostridia, a highly polyphyletic class of Firmicutes ${ }^{4,9}$, process dietary fibers that are not degraded by the stomach acidic and tryptic environment (resistant fibers) to yield short-chain fatty acids (SCFAs), mostly butyrate ( 4 carbons) $)^{10}$, propionate ( 3 carbons), and acetate ( 2 carbons). These SCFAs can modulate mammalian cell functions by serving as energy substrate or by signaling through G-protein-coupled receptors (GPCRs) ${ }^{1,10-13}$. In addition, they directly inhibit histone deacetylases (HDACs) to modulate gene expression ${ }^{11,14,15}$. HDACs remove histone lysine acetyl groups, leading to chromatin condensation and transcriptional silencing. By blocking HDAC-mediated histone deacetylation, butyrate and propionate effectively hyperacetylate histones, thereby enhancing chromatin accessibility and activating gene expression ${ }^{1,10,16}$. Histone acetylation/deacetylation modulates cell gene expression without modifying genomic DNA sequence (epigenetic modification). Other major epigenetic modifications and factors include histone methylation and glycosylation, DNA methylation/demethylation, and noncoding RNAs, such as microRNAs (miRNAs) and long noncoding RNAs (lncRNAs), all of which influence gene transcriptional, post-transcriptional, and posttranslational processes ${ }^{5-7}$.

Gut concentration of SCFAs depends on host's dietary fiber intake, gut bacterial composition, intestinal transit time, and host-microbiota metabolite flux ${ }^{1,17,18}$. Germ-free animals, which have no gut microbiota, show very low levels of gut and periphery SCFAs ${ }^{15,19,20}$, as do mice in a normal environment, but fed a lowfiber or no-fiber diet ${ }^{20,21}$. Dietary fibers and gut microbiota contribute to overall levels of SCFAs. These, particularly butyrate and propionate, impact immune responses locally, in intestinal mucosa and lumen, and systemically, throughout body districts ${ }^{1-}$ $4,10,18$, thereby maintaining a healthy immune homeostasis and prevent allergy and autoimmunity ${ }^{22,23}$. In addition, SCFAs reduce expression of co-stimulatory molecules on antigenpresenting cells, prompting a tolerogenic phenotype, as driven by HDAC inhibition and GPR109A signaling ${ }^{24}$. They can also affect bone marrow hematopoiesis by enhancing generation of dendritic cell (DC) precursors with impaired ability to promote $\mathrm{T}$ helper type 2 (Th2) cell effector function ${ }^{20}$. Finally, butyrate and propionate promote thymic production of FOXP3 ${ }^{+}$Tregs and peripheral conversion of $\mathrm{T}$ cells into FOXP3 ${ }^{+}$Treg cells ${ }^{22,25}$, through histone (H3) acetylation (by HDAC inhibitory activity) within key regulatory regions of the Foxp3 locus ${ }^{15,25}$.

SCFAs would mitigate autoimmunity by regulating T cells, DCs, innate lymphoid cells (ILCs), and macrophages 2,3,15,19,20,24,26-29, increasing anti-inflammatory cytokines, such as TGF- $\beta$ and IL-10, and inhibiting production of proinflammatory cytokines, such as IL-6, IL-12, IL-17a, IFN- $\gamma$, and TNF- $\alpha^{1,3,30-32}$. They can reduce recruitment of eosinophils and allergic cellular infiltration of airways, thereby dampening inflammation and $\operatorname{IgE}$ antibody respon$\operatorname{ses}^{20}$. Butyrate and/or propionate may indirectly affect $\mathrm{B}$ cells by modulating functions of Treg cells, particularly in autoimmune

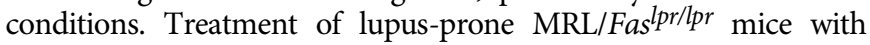
HDAC inhibitor (HDI) drugs, such as valproic acid (VPA), panobinostat (Farydak), vorinostat (SAHA, Zolinza), or romidepsin (Istodax), reduce autoreactive plasma cell numbers, nephritis, and dampened autoimmunity ${ }^{33,34}$. Other HDIs, such as suberoylanilide hydroxamic acid (SAHA), Trichostatin-A (TSA), and bufexamac, exhert anti-inflammatory effects ${ }^{22}$. As we have shown, VPA, a strong HDAC inhibitor used for epileptic seizures ${ }^{35}$, acts directly on B cells to downregulate AICDA/Aicda and PRDM1/Prdm1 expression in a dose-dependent fashion ${ }^{7,8,33}$. HDAC inhibitory drugs are effective against B lymphocyte lineage malignancies, by inhibiting cell proliferation, survival, and differentiation in an HDAC-classdependent manner ${ }^{36,37}$. By boosting B-cell metabolism and plasma cell differentiation ${ }^{12}$, SCFAs would potentially support the antibody response, although this contrasts with a large body of evidence emphasizing a potent immunosuppressive activity of gut fiberderived SCFAs $1,4,9,10,20,22,25,34,38-40$. Thus, whether and how SCFAs impact B-cell differentiation and/or functions remains to be elucidated.

Here, we show that butyrate and propionate act directly on mouse and human B cells to inhibit AID and Blimp1 expression through a B cell-intrinsic, dose-dependent epigenetic HDAC inhibitory activity (not as energy substrate or through GPCR signaling) that leads to upregulation of select miRNAs targeting Aicda- and Prdm1-3'UTRs. The impact of these SCFAs on B cells in vivo was analyzed by feeding mice a diet-containing fibers (regular chow) or no fiber, together with or without exogenous butyrate and propionate in water. SCFAs concentrations were monitored in the circulation, tissues and feces together with $\operatorname{IgD}$, IgG, IgA, IgE, and bacteria-bound antibodies. Mice fed a no-fiber diet reduced fecal SCFAs, and increased serum and fecal classswitched antibodies. This was reversed by administration of exogenous butyrate and propionate. Through downregulation of B cell AID and Blimp1, these SCFAs inhibited class-switch DNA recombination (CSR), somatic hypermutation (SHM), and plasma cell differentiation in $\mathrm{T}$-dependent and $\mathrm{T}$-independent antibody responses in C57BL/J6 mice, $\operatorname{Tcr} \beta^{-/-} \mathrm{Tcr} \delta^{-/-}$mice, and NOD-scid IL2ry null (NSG) mice grafted with purified B cells. The SCFAs B-cell modulatory potency extended to autoantibody responses in lupus-prone MRL/Fas ${ }^{l p r / p r}$ and NZB/W F1 mice. Thus, SCFAs derived from gut microbiota-processed dietary fibers modulate antibody and autoantibody responses by impacting directly B-cell-intrinsic epigenetic mechanisms through their HDAC inhibitory activity.

\section{Results}

Fiber-derived SCFAs reduce local and systemic antibody responses. To address the impact of dietary fiber SCFAs on the antibody response, we fed (after weaning) ten C57BL/6 mice a fiber diet (regular chow, 18\% fiber content) and ten mice a nofiber diet ( $0 \%$ fiber). Two weeks later (at the age of 5 weeks), five mice in each group were started on water-containing SCFAs $(20.0 \mathrm{mg} / \mathrm{ml}$ tributyrin, $140 \mathrm{mM}$ sodium butyrate, and $150 \mathrm{mM}$ sodium propionate, $\mathrm{pH} 7.4$ ), and the other five mice on plain water ( $\mathrm{pH} 7.4$ and $\mathrm{Na}^{+}$adjusted to match SCFAs water). All mice were then administered ovalbumin (OVA) together with cholera toxin (CT) via intragastric gavage, once a week for 4 weeks. In mice fed fiber diet (regular chow) and plain water, the concentration of butyrate in feces, colon tissue, spleen, and mesenteric lymph nodes (MLNs) were $7.92,0.46,0.59$, and $0.33 \mu \mathrm{mol}$ $\mathrm{g}^{-1}$, respectively, and those of propionate were $6.28,0.67,1.14$, and $0.61 \mu \mathrm{mol} \mathrm{g} \mathrm{g}^{-1}$, respectively (Supplementary Fig. 1a). In circulation, butyrate and propionate were 5-80 $\mu \mathrm{M}$. SCFAs water to mice on fiber diet increased butyrate and propionate in feces (12.1-23.4 and $13.7-25.9 \mu \mathrm{mol} \mathrm{g}^{-1}$, respectively), colon tissue (1.38; $\left.1.88 \mu \mathrm{mol} \mathrm{g} \mathrm{g}^{-1}\right)$, spleen $\left(1.43 ; 2.56 \mu \mathrm{mol} \mathrm{g} \mathrm{g}^{-1}\right)$, MLNs (1.07; $\left.1.75 \mu \mathrm{mol} \mathrm{g}{ }^{-1}\right)$, and circulation $(20-200 \mu \mathrm{M})$. These levels were comparable with those in mice or humans fed a fiber or high-fiber $\operatorname{diet}^{20,41}$, and led to reduced fecal and circulating levels of total and OVA-specific IgG1, IgA, and IgE (Fig. 1a, b).

The mice fed no-fiber diet and plain water displayed a low level of butyrate and propionate in feces (butyrate, $1.1-1.8 \mu \mathrm{mol} \mathrm{g}^{-1}$; 

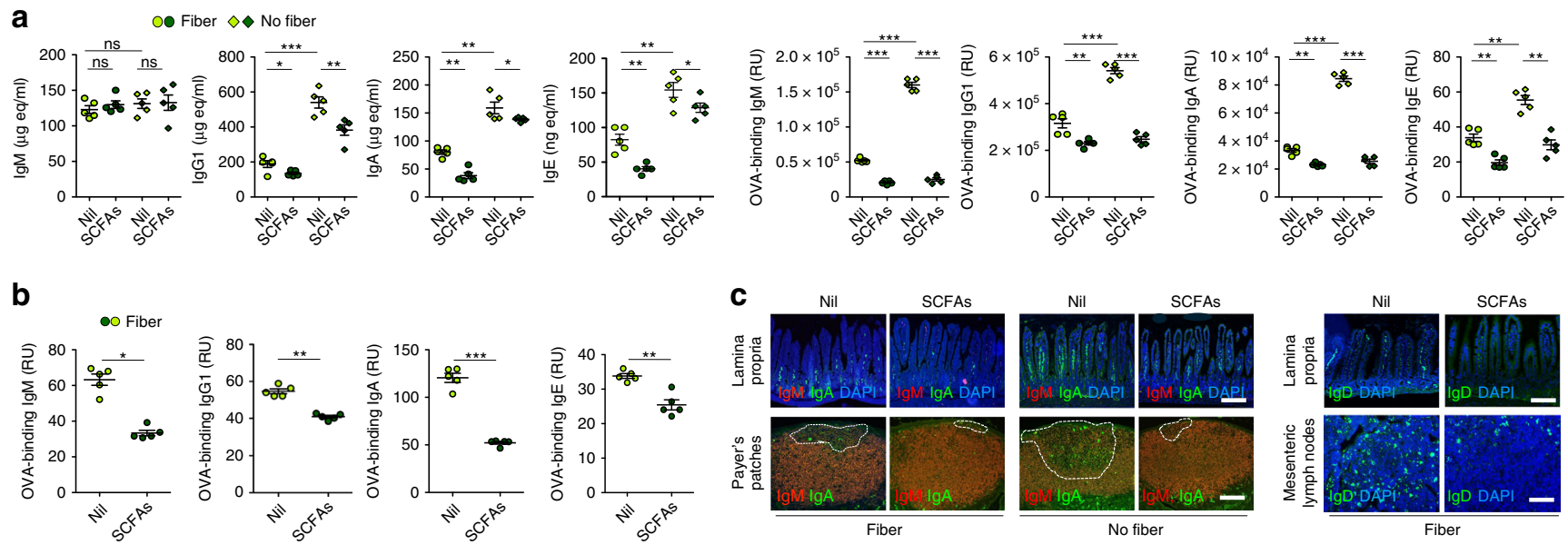

d

Total AFCs
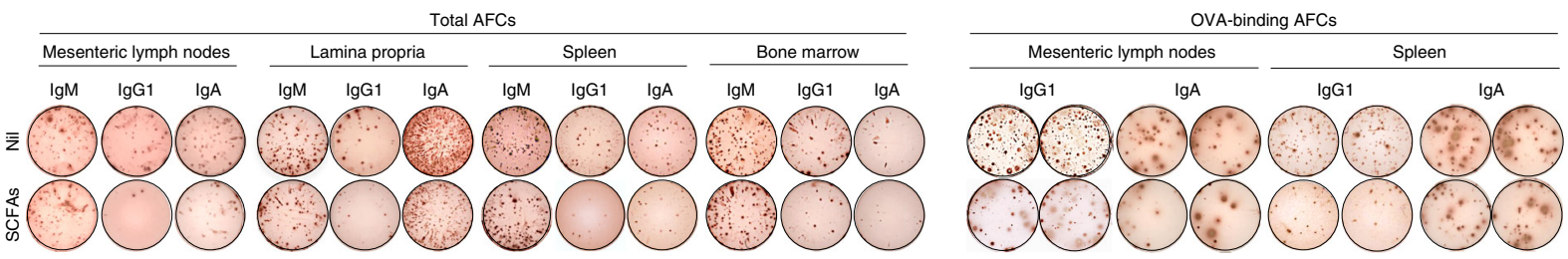

e
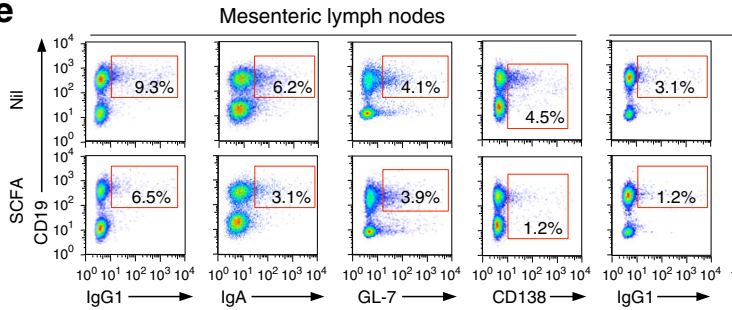

Peyer's patches
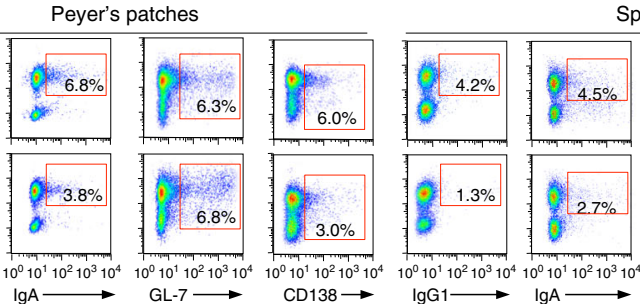

Spleen

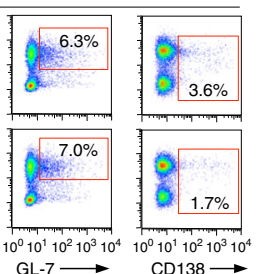

Fig. 1 Dietary fibers and SCFAs dampen CSR, plasma cell differentiation and class-switched antibody responses. After weaning, C57BL/6 mice were fed a fiber diet (regular chow) or no-fiber diet. Two weeks later, these mice were started on SCFAs water (SCFAs) or plain water (Nil). All mice were then administered OVA together with CT via intragastric gavage once a week for 4 weeks starting at 8 weeks of age, and killed a week after the last OVA and CT administration. a Total and OVA-binding $\lg M, \operatorname{lgG} 1, \lg A$, and $\lg E$ concentrations in serum of fiber or no-fiber-fed mice on SCFAs water or plain water, as measured by ELISA. Each symbol represents an individual mouse ( $n=5$ per group, pooled from two experiments). The bars represent the mean \pm SD. $\mathbf{b}$ OVA-binding IgM, IgG1, IgA, and IgE concentrations in the feces of fiber-fed mice on SCFAs water or plain water, as measured by ELISA. Each symbol represents an individual mouse ( $n=5$ per group, pooled from two experiments). c IgM, IgA, and IgD-positive cells in the lamina propria, PPs, and MLNs of fiber or no-fiber-fed mice on SCFAs water or plain water as visualized by fluorescence microscopy. $\mathbf{d}$ ELISPOT analysis of IgM, IgG1, and IgA AFCs in MLNs, PPs, spleen, and bone marrow of fiber-fed mice on SCFAs water or plain water. e Proportion of surface $\mathrm{CD} 19^{+} \operatorname{lgG} 1^{+}$and $\mathrm{CD} 19^{+} \mathrm{IgA}{ }^{+} \mathrm{B}$ cells, germinal center B cells $\left(\mathrm{CD} 19^{+} \mathrm{GL}-7^{+}\right)$, and plasmablasts/plasma cells $\left(\mathrm{CD} 138^{+}\right)$in $\mathrm{MLNs}$, PPs, and the spleen of fiber-fed mice given SCFAs water or plain water, as analyzed by flow cytometry. Data in c-e are representative of three independent experiments. ${ }^{\star} p<0.05,{ }^{\star \star} p<0.01,{ }^{\star \star \star} p<0.001$, ns: not significant (unpaired $t$ test). Scale bar $=100 \mu \mathrm{m}$. The source data are provided in Source Data file.

propionate, 1.1-2.1 $\mu \mathrm{mol} \mathrm{g}^{-1}$ ) and high levels of total and OVAspecific IgG1, IgA, and IgE, which upon administration of SCFAs were brought down to the levels observed in fiber diet-fed mice on SCFAs water (Supplementary Fig. 1a; Fig. 1a, b) - acetate was not used in these in vivo experiments, as this SCFA does not display a significant HDAC inhibitory activity ${ }^{11,14,15}$ and it did not alter Aicda or Prdm1 expression and CSR or plasma cell differentiation (Supplementary Fig. 1b-d). When added to the fiber diet, exogenous butyrate and propionate further decreased circulating class-switched antibodies and local (intestinal) IgAand IgD-expressing cells in Peyer's patches (PPs), lamina propria (LP), and/or MLNs, as well as the total IgG1 and IgA but not IgM antibody-forming cells (AFCs) in LP, MLNs, spleen, and bone marrow. The local and systemic reduction in AFCs was associated with decreased numbers of $\operatorname{IgA}^{+}$and $\operatorname{IgG1}^{+}$B cells, as well as $\mathrm{CD}_{138^{+}}$plasmablasts/plasma cells, but not germinal center (GL$\left.7^{+}\right)$B cells in PPs, MLNs, and spleen of SCFA-treated fiber-fed mice (Fig. 1c-e; Supplementary Fig. 2). By contrast, the no-fiber diet increased intestinal and systemic class-switched B cells, AFCs, and antibody levels, which were reduced by administration of exogenous SCFAs. The reduction of local and systemic classswitched B cells, AFCs, and class-switched antibodies by SCFAs reflected an inhibition of AID and Blimp1 expression (Fig. 2a-c; Supplementary Fig. 2), and was associated with increased fecal butyrate $\left(12.7\right.$ vs. $\left.1.4 \mu \mathrm{mol} \mathrm{g}{ }^{-1}\right)$ and propionate $(14.2$ vs. $1.5 \mu \mathrm{mol}$ $\mathrm{g}^{-1}$ ) in mice fed a no-fiber or fiber diet in conjunction with exogenous SCFAs (Supplementary Fig. 1a). Thus, butyrate and propionate from fermentation of dietary fibers reduced B cell AID and Blimp1, class-switched B cells, AFCs, and class-switched antibodies at local (intestinal) and systemic levels.

SCFAs dampen systemic and fecal anti-bacteria antibodies. Exogenous SCFAs further reduced B-cell expression of AID and Blimp1 as well as fecal bacteria-bound IgD, IgG1, and IgA but not the (low) level of bacteria-bound IgM (virtually no bacteria- 


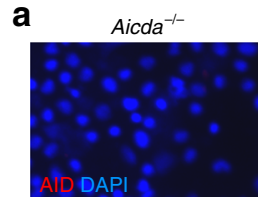

Naive B cell

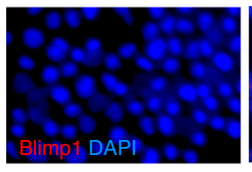

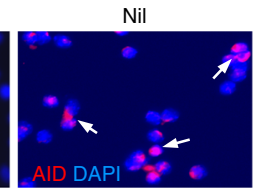

Nil

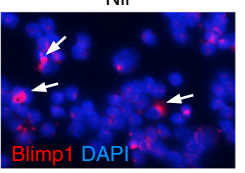

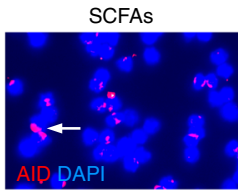

SCFAs

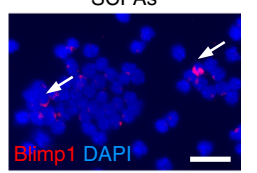

C

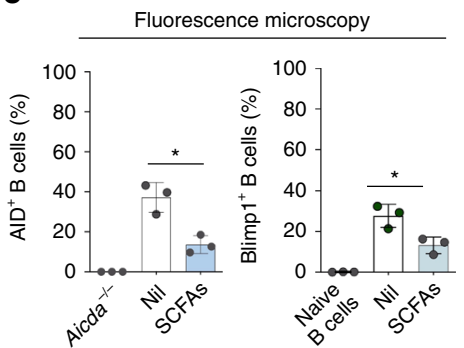

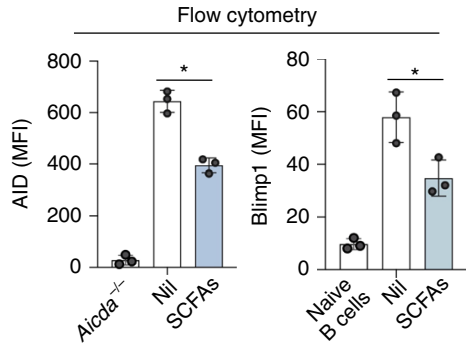

e

e Feces: bacteria-bound IgA

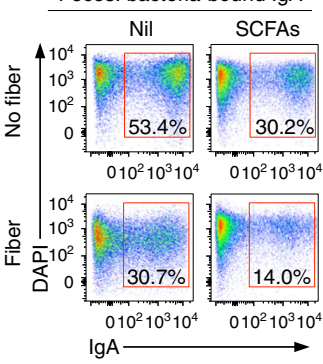

h

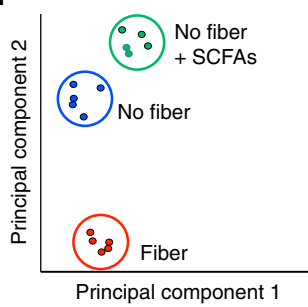

d

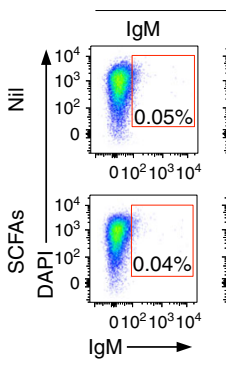

Feces: bacteria-bound antibodies
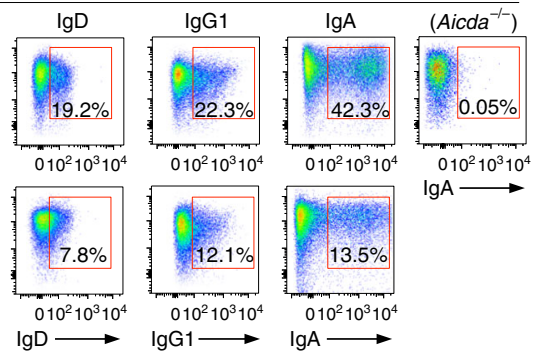

g

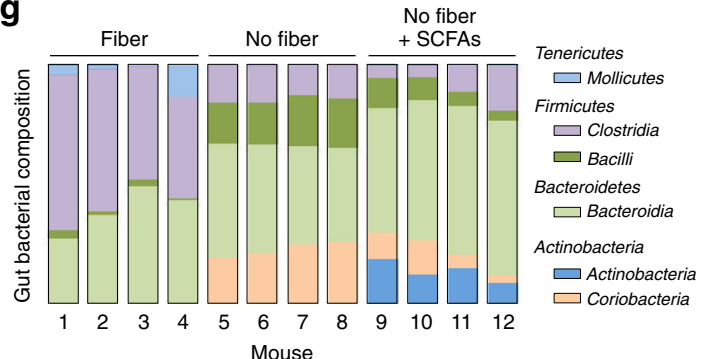

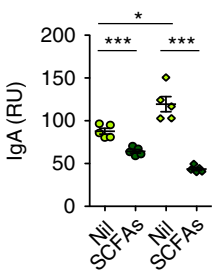

- Fiber $\diamond \diamond$ No fiber

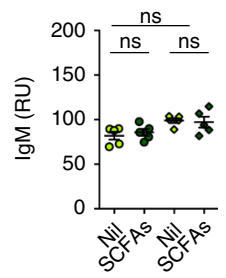

Fig. 2 Dietary fibers and SCFAs alter AID and Blimp1 expression, bacteria-bound/binding antibody responses, and gut bacteria composition. C57BL/ 6 mice fed a fiber or no-fiber diet were on SCFAs water (SCFAs) or plain water (nil) and administered OVA together with CT (same as in Fig. 1). $\mathbf{a}$, b AID and Blimp1 expression in spleen B cells of these mice, AID expression in spleen B cells of Aicda ${ }^{--}$mice, and Blimp1 expression in naive B cells of C57BL/6 mice, as analyzed by intracellular staining followed by fluorescence microscopy (a) and flow cytometry (b). c Quantification of AID ${ }^{+}$and Blimp ${ }^{+}$cells in $\mathbf{a}$ and $\mathbf{b}$.

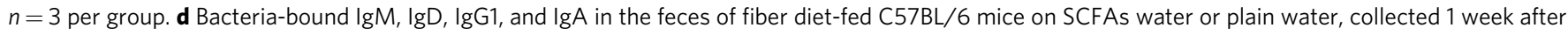
the last OVA and CT administration, as well as bacteria-bound lgA in the feces of unimmunized Aicda $/-$ mice fed fiber diet and plain water, as analyzed by flow cytometry. e Bacteria-bound IgA in feces of fiber and no-fiber diet-fed mice on SCFAs water or plain water as analyzed by flow cytometry.

f Concentration of bacteria-binding $\operatorname{lgM}$ and $\lg A$ in the serum as measured by ELISA; each symbol represents an individual mouse ( $n=5$ per group, pooled from two experiments). The bars represent the mean \pm SD. $\mathbf{g}$ Relative abundance of gut bacteria classes (> $1 \%$ in any sample group; fiber, no-fiber, and nofiber + SCFAs) in the mice ( $n=4$ per group, pooled from two experiments) as determined by high-throughput 16s rRNA gene miSeq sequencing.

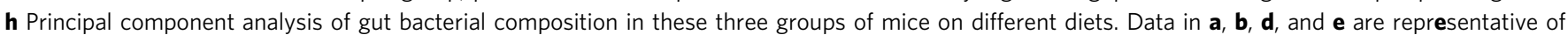

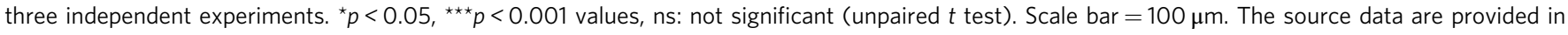
Source Data file.

bound IgA were detected in $\mathrm{Aicda}^{-/-}$mice) in mice on fiber diet. In the absence of exogenous SCFAs, mice on fiber diet (regular chow) reduced fecal bacteria-bound IgA and circulating bacteriabinding IgA in fiber vs. no-fiber-fed mice, without altering circulating levels of bacteria-binding IgM (Fig. 2a-f; Supplementary Fig. 2). To address the influence of dietary fibers and SCFAs on gut bacterial composition, we performed high-throughput sequencing of fecal bacterial $16 \mathrm{~S}$ rRNA genes. The fiber or nofiber diet with or without exogenous SCFAs resulted in comparable gut microbial composition in all four mice of each diet group (Fig. 2g). Firmicutes Clostridia and Firmicutes Bacilli as well as Bacteriodetes Bacteroidia, which are major SCFAs producers ${ }^{9}$, were present in all three dietary groups, albeit at different frequencies. These were conditioned mainly by the presence or absence of dietary fibers, as exogenous SCFAs diversified gut bacterial composition only marginally (principal component analysis, Fig. 2h).
SCFAs dampen hypermutated and class-switched antibody responses. In addition to dampening class-switched IgG1, IgA, and IgE to OVA, SCFAs reduced circulating OVA-binding IgM titers, but not total IgM. We reasoned that the reduced OVA-binding IgM but not total IgM resulted from inhibition of SHM by butyrate and propionate and, consequently, impaired antibody affinity maturation. To address the impact of SCFAs on SHM, we injected eight C57BL/6 mice with $\mathrm{NP}_{16}$-CGG i.p., and fed four of such mice SCFAs water and the other four plain water. SCFAs did not affect the overall level of total $\operatorname{IgM}$, but reduced total IgG and IgA as well as (high affinity) $\mathrm{NP}_{3}$-binding IgM, IgG, and $\operatorname{IgA}$, likely a reflection of the $66 \%$ decrease in somatic mutations of the recombined $\mathrm{V}_{186.2}$ gene segment, which encodes the NP-binding site (Fig. 3a, c).

As a first step toward addressing the SCFAs-mediated Tindependent, and possibly B-cell-intrinsic, modulation of the antibody response, we fed four C57BL/6 mice SCFAs water and 
a

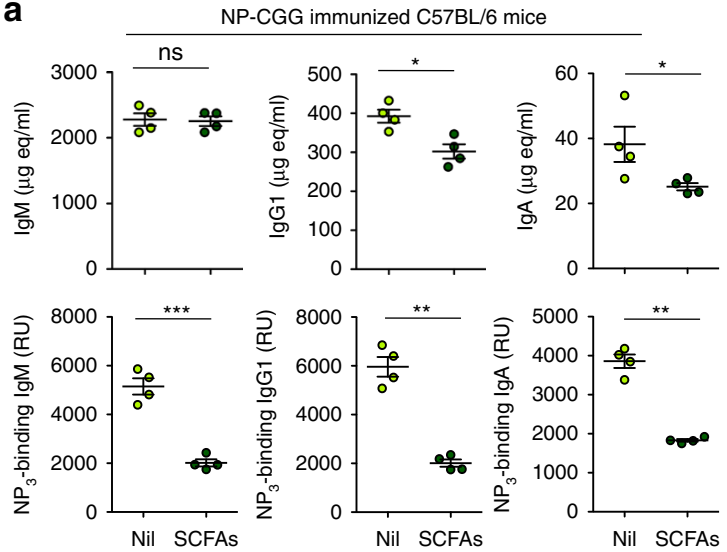

C

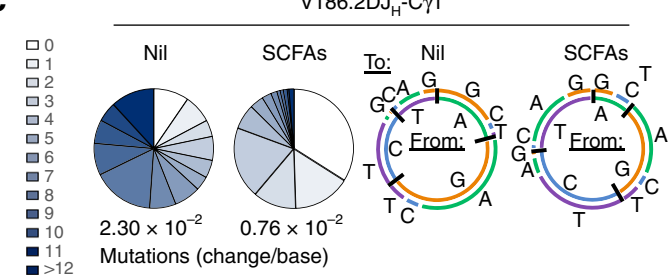

b

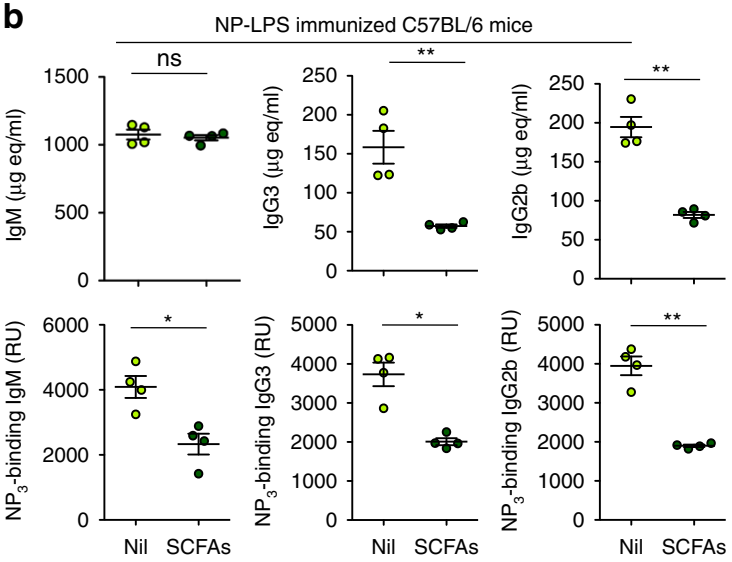

d

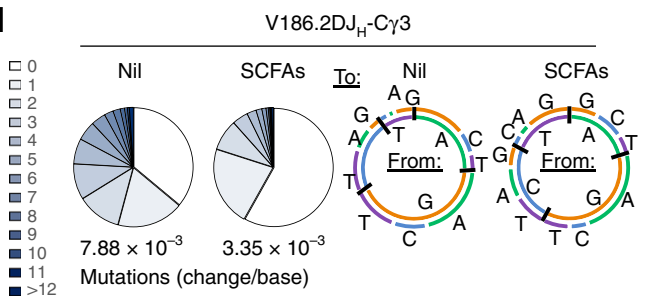

e NP-LPS immunized TCR $\beta^{-1-} T C R \delta^{-/}$mice

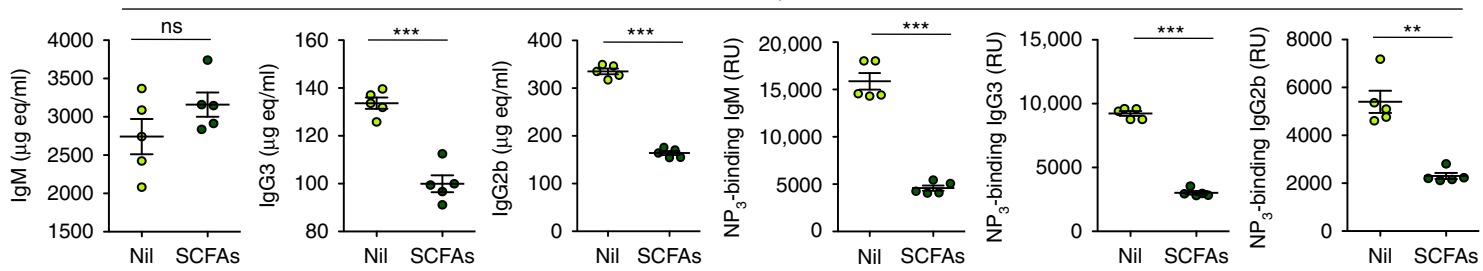

f

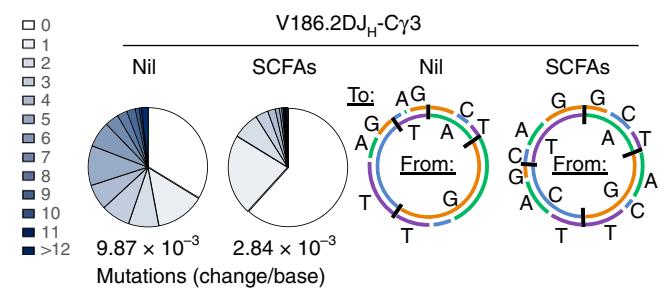

g
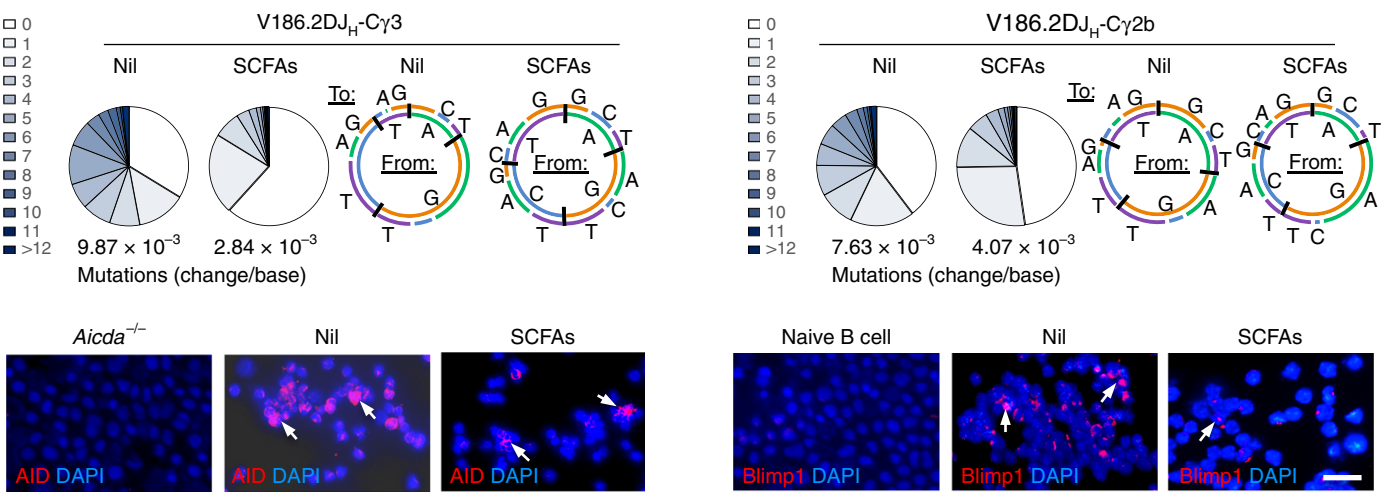

h

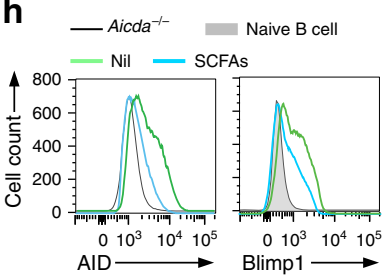

i

Fluorescence microscopy
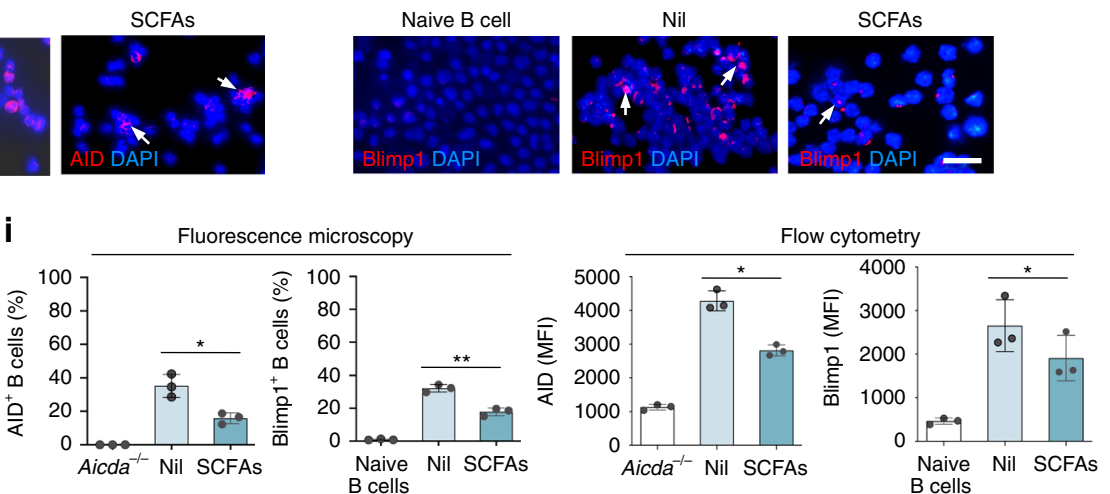

another four plain water, and then i.p. injected all of them with NP-LPS. SCFAs curtailed the T-independent class-switched and high-affinity $\mathrm{NP}_{3}$ (exclusively IgG3 and IgG2b) antibody response, with a significantly lower mutational load in recombined $\mathrm{V}_{186.2}$ gene segments, albeit of different magnitude from that of the T-dependent response. This occurred without changes in proportion of $\mathrm{B} 220^{+} \mathrm{B}$ cells, $\mathrm{CD}^{+}, \mathrm{CD}^{+}$, and $\mathrm{CD} 8^{+} \mathrm{T}$ cells, or B-cell proliferation, viability, and germinal center formation (Fig. 3b, d; Supplementary Fig. 3a, b, e).

To further show that SCFAs can impair the maturation of the antibody response independently of T cells, we analyzed the anti$\mathrm{NP}_{3}$ IgG3 and IgG2b response in ten $T c r \beta^{-/-} \mathrm{Tcr} \delta^{-/}$mice (devoid of both $\alpha \beta^{+}$and $\gamma \delta^{+} \mathrm{T}$ cells $\left.{ }^{42}\right)$. These mice were divided into two groups of five each, which were fed plain or SCFAs water, and 
Fig. 3 SCFAs reduce class-switched and hypermutated T-dependent and T-independent antibody responses. a-d C57BL/6 mice fed fiber diet on SCFAs water (SCFAs) or plain water (Nil) starting at the age of 5 weeks, and i.p. injected with NP 16 -CGG (in Alum) or NP-LPS (in PBS) at the age of 8 weeks. The mice were boost-injected 3 weeks later with $\mathrm{NP}_{16}-\mathrm{CGG}$ or NP-LPS, respectively, and killed a week after the boost injection. $\mathbf{a}$, $\mathbf{b}$ Titers of total and $\mathrm{NP}_{3}$ binding serum IgM, IgG1, and IgA in $\mathrm{NP}_{16}$-CGG injected C57BL/6 mice (a), as well as total and $\mathrm{NP}_{3}$-binding serum IgM, IgG3, and IgG2b titers in NP-LPS injected C57BL/ 6 mice (b), as measured by ELISA ( $n=4$ per group, pooled from two experiments). Bars represent the mean \pm SD. $\mathbf{c}$, $\mathbf{d}$ Somatic point mutations in the $V_{186.2}$ regions from $V_{186.2} D J_{H^{-}}-C \gamma 1$ transcripts of $N P_{16}-C G G$ injected C57BL/6 mice (c), or from $V_{186.2} D J_{H^{-}}-C \gamma 3$ transcripts of the NP-LPS injected C57BL/6 mice (d). Sequence data were pooled from three mice in each group. Pie charts depict the proportions of sequences that carry different numbers of point mutations; listed below the pie charts is the overall mutation frequency (change/base). Donut charts depict the spectrum of point mutations. e-h $\mathrm{Tcr} \beta^{-/-} \mathrm{Tcr} \delta^{-/-}$mice on SCFAs water or plain water were injected with NP-LPS. Total and $\mathrm{NP}_{3}$-specific serum IgM, IgG3, and IgG2b titers were measured by ELISA ( $n=5$ per group) (e). Somatic point mutations in the $V_{186.2}$ region of $V_{186.2} D J_{H^{-}}-C \gamma 3$ and $V_{186.2} D J_{H^{-}} C \gamma 2 b$ transcripts. Sequence data were pooled from three mice in each group (f). AID and Blimp1 expression in spleen B cells of these mice, AID expression in spleen B cells of Aicda ${ }^{-}-$ mice, and Blimp1 expression in naive B cells of C57BL/6 mice, as analyzed by intracellular staining followed by fluorescence microscopy ( $\mathbf{g}$ ), and flow cytometry (h). Data in $\mathbf{g}$ and $\mathbf{h}$ are representative of three independent experiments. $\mathbf{i}$ Quantification of AID ${ }^{+}$and Blimp $1^{+}$cells in $\mathbf{h}$ and $\mathbf{g} . n=3$ per group. ${ }^{\star} p<0.05,{ }^{\star \star} p<0.01,{ }^{\star \star \star} p<0.001$ (unpaired $t$ test). Scale bar $=10 \mu \mathrm{m}$. The source data are provided in Source Data file.

then i.p. injected with NP-LPS. The Tcr $\beta^{-/-} T c r \delta^{-/-}$mice fed plain water mounted a robust class-switched and hypermutated antibody response to NP. Such a response was reduced by SCFAs in term of total and high-affinity $\mathrm{NP}_{3}$-specific IgG3 and IgG2b, likely reflecting the defective $\mathrm{CSR}$ and decreased somatic point mutations in $\mathrm{V}_{186.2}$ segment of $\mathrm{V}_{186.2} \mathrm{DJ}_{\mathrm{H}^{-}} \mathrm{C} \gamma 3$ and $\mathrm{V}_{186.2} \mathrm{DJ}_{\mathrm{H}^{-}}$ C 2 b transcripts (by $71 \%$ and $47 \%$ ). The SCFA-mediated inhibition of CSR/SHM was directly associated with reduced Bcell expression of AID and Blimp1, and normal germinal center formation (Fig. 3e-i; Supplementary Figs. 3c, 4, 5).

Having shown that fiber-derived SCFAs inhibit antibody responses at intestinal and systemic levels, we addressed the suggestion that at a low concentration, SCFAs increase IgG and IgA responses ${ }^{12}$. To this end, we fed five C57BL/6 mice SCFAs water, and five mice water containing a low dose of SCFAs (20 $\mathrm{mM}$ sodium butyrate and $30 \mathrm{mM}$, comparable with what used by Kim et $\mathrm{al}^{12}$ ). A third group of five mice were fed plain water. All mice were injected with NP-LPS. While SCFA water significantly reduced total and $\mathrm{NP}_{4}$-binding IgG2b and IgG3, B cell AID and Blimp1 expression, IgG3 ${ }^{+}$and IgG $2 b^{+}$B cells, as well as plasma cells, low- dose SCFA water led to a moderate increase in AID and Blimp1 expression, IgG2 $\mathrm{b}^{+}$and $\mathrm{IgG}^{+} \mathrm{B}$ cells, and $\mathrm{CD} 19^{\text {low }} \mathrm{CD} 138^{+}$plasma cells, as well as circulating total and NP-binding IgG2b and IgG3 (Fig. $4 \mathrm{a}-\mathrm{c}$ ).

To further address the direct B-cell-intrinsic SCFA-mediated impairment of the antibody response in vivo, we developed "NSG/B" mice by engrafting immuno-deficient NOD-scid IL2ry ${ }^{\text {null }}$ (NSG) mice ${ }^{43}$, which lack T cells, B cells, NK cells, functional DCs, and macrophages, with highly purified C57BL/ 6 spleen B cells. We segregated ten NSG/B mice into two groups, each of five mice. One group was fed SCFAs water and the other plain water, all of them were then i.p. injected with NP-LPS. All NSG/B mice fed plane water made IgM, IgG2b, IgG3, and IgA antibodies to $\mathrm{NP}_{3}$. However, the NSG/B mice given SCFAs water reduced total and $\mathrm{NP}_{3}$-binding $\operatorname{IgG} 3, \operatorname{IgG} 2 \mathrm{~b}$ and $\operatorname{IgA}$, as well as $\mathrm{NP}_{3}$-binding but not total IgM, likely reflecting the reduced number of spleen $\mathrm{NP}_{3}$-specific IgM-, IgG3-, IgG2b-, and IgA AFCs, in the absence of altered B-cell viability or number (Fig. 4d-f). This was underpinned by reduced Aicda and Prdm1 expression and decreased post-recombination $\mathrm{I} \mu-\mathrm{C} \gamma 3$, I $\mu-\mathrm{C} \gamma 2 \mathrm{~b}$, and $\mathrm{I} \mu-\mathrm{C} \alpha$ transcripts, and was concomitant with reduced numbers of $\mathrm{IgG3}^{+}$and $\mathrm{IgG}^{+} \mathrm{b}^{+} \mathrm{B}$ cells, as well as $\mathrm{CD} 138^{+}$ plasmablasts/plasma cells; exogenous SCFAs also reduced (by $40.3 \%$ ) the mutational load in $\mathrm{V}_{\mathrm{H}} \mathrm{DJ}_{\mathrm{H}}-\mathrm{C} \gamma 2 \mathrm{~b}$ transcripts (Fig. $4 \mathrm{~g}-\mathrm{i}$ ). Thus, SCFAs can impair the maturation of a class-switched highaffinity antibody response by downregulating Aicda and Prdm1 expression, thereby dampening CSR/SHM and plasma cell differentiation, in a T-cell-, DC-, NK cell-, and macrophageindependent, and B-cell-intrinsic fashion.
Dose-dependent B cell AICDA/Aicda and PRDM1/Prdm1 inhibition by SCFAs. To define the direct and B-cell-intrinsic impact of SCFAs on Aicda and Prdm expression, we induced mouse $B$ cells to undergo CSR to IgD, IgG1, IgA, IgE, and plasma cell differentiation in the presence of nil, butyrate $(50-500 \mu \mathrm{M})$, propionate $(50-2000 \mu \mathrm{M})$, or butyrate $(500 \mu \mathrm{M})$ plus propionate $(1000 \mu \mathrm{M})$. The butyrate and propionate concentrations used in these in vitro experiments were within the range of those detected in the spleen, colon, and MLNs (Supplementary Fig. 1a). Butyrate and propionate decreased CSR to all Ig isotypes and plasma cell differentiation in a dose-dependent fashion without altering Bcell viability or proliferation, as exemplified by the lower proportion of class-switched $\mathrm{IgG1}^{+} \mathrm{B}$ cells in each round of cell division (Fig. 5a-h and Supplementary Figs. 3d, f, 6, 7). The inhibition of CSR and plasma cell differentiation by butyrate (500 $\mu \mathrm{M})$ and propionate $(2000 \mu \mathrm{M})$ was further confirmed by decreased IgG1 and IgA secretion, decreased post-recombination $\mathrm{I} \mu-\mathrm{C} \gamma 1, \mathrm{I} \mu-\mathrm{C} \alpha$ and $\mathrm{I} \mu-\mathrm{C} \varepsilon$ transcripts, reduced Aicda and Prdm 1 transcripts, and AID and Blimp1 proteins. Germline $\mathrm{I} \mu-\mathrm{C} \mu$, $\mathrm{I} \gamma 1-\mathrm{C} \gamma 1$, I $\alpha-\mathrm{C} \alpha$, and $\mathrm{I} \varepsilon-\mathrm{C} \varepsilon$ transcripts, which are also involved in CSR, were not reduced, rather increased by butyrate and propionate in a dose-dependent fashion, likely due to the HDAC inhibitory activity of such SCFAs (Fig. 5i-l; Supplementary Fig. 8a). To define whether SCFA acetate also affects CSR and plasma cell differentiation, we stimulated B cells with LPS and IL4 , in the presence of increasing doses of acetate or acetate together with butyrate or propionate. As predicted, unlike butyrate and propionate, acetate did not alter Aicda and $\operatorname{Prdm} 1$ expression or CSR to IgG1 and plasma cell differentiation (Supplementary Fig. 1b, c), nor did it affect Aicda and Prdm1 inhibition by butyrate and propionate (Supplementary Fig. 9). To define whether, like what we found in vivo, low and higher SCFAs concentrations modulate differentially CSR and plasma cell differentiation, we stimulated B cells with LPS plus IL-4 in the presence of increasing concentrations of SCFAs (butyrate, 50-800 $\mu \mathrm{M}$; propionate, $50-3200 \mu \mathrm{M}$ ). At concentrations comparable to or higher than those in colon and lymphoid tissues of mice fed a fiber diet and plain water (butyrate, $\geq 400 \mu \mathrm{M}$; propionate, $\geq 800 \mu \mathrm{M}$ ), butyrate and propionate inhibited Aicda expression in a dose-dependent fashion. By contrast, at low concentrations (butyrate, 50,100, or $200 \mu \mathrm{M}$; propionate, 50, 100, 200, or $400 \mu \mathrm{M})$, these SCFAs moderately increased Aicda expression (Supplementary Fig. 8a).

As they did in mouse B cells, butyrate and propionate inhibited CSR to IgG, IgA, and IgE, as well as plasma cell differentiation in human $\mathrm{B}$ cells in a dose-dependent fashion. They reduced the number of surface $\mathrm{IgG}^{+}$and $\mathrm{IgA}^{+} \mathrm{B}$ cells, decreased secreted IgG and $\operatorname{IgA}$ as well as mature post-recombination $\mathrm{V}_{\mathrm{H}} \mathrm{DJ} \mathrm{H}^{-} \mathrm{C} \gamma 1$, $\mathrm{V}_{\mathrm{H}} \mathrm{DJ}_{\mathrm{H}^{-}} \mathrm{Ca}$, and $\mathrm{V}_{\mathrm{H}} \mathrm{DJ}_{\mathrm{H}^{-}} \mathrm{C} \varepsilon$ transcripts, without altering $\mathrm{B}$-cell 
a Nil $\bigcirc$ SCFAs (lower dose) $\bigcirc$ SCFAs (higher dose)
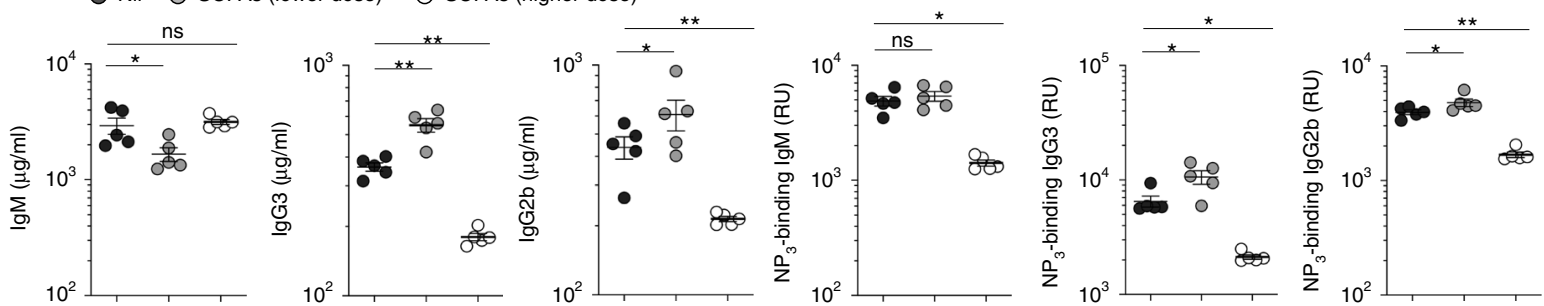

b

Isotype control

Nil

- SCFAs (lower dose)
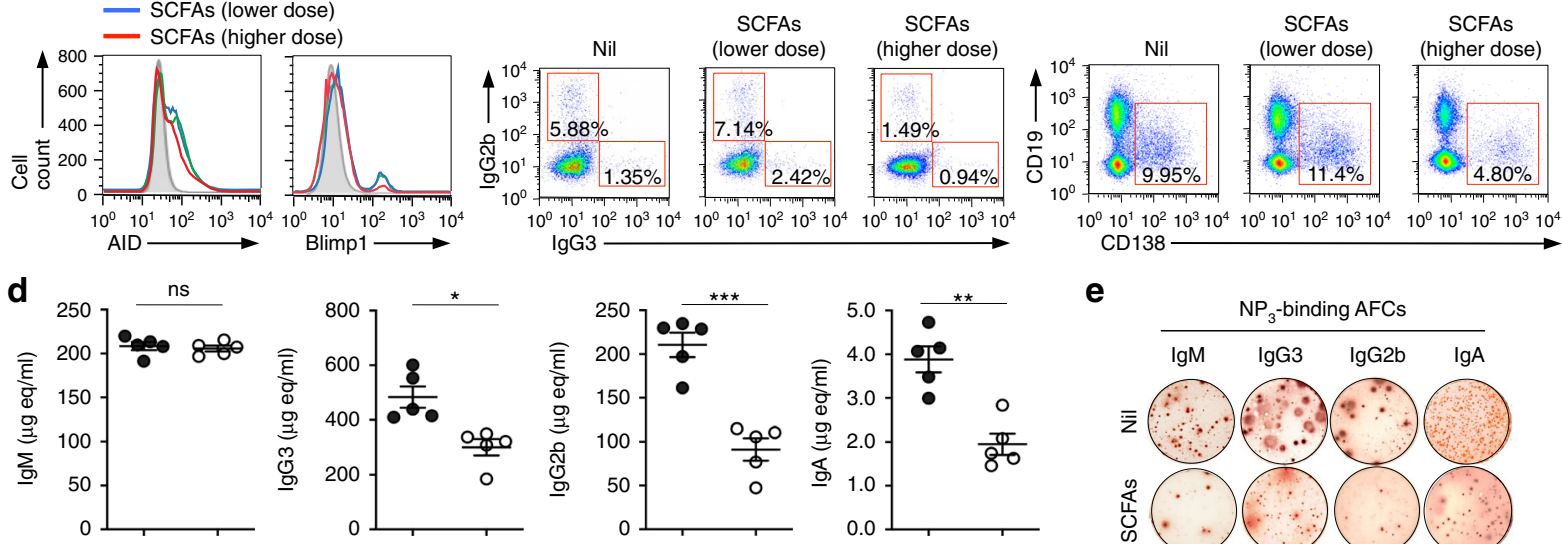

e
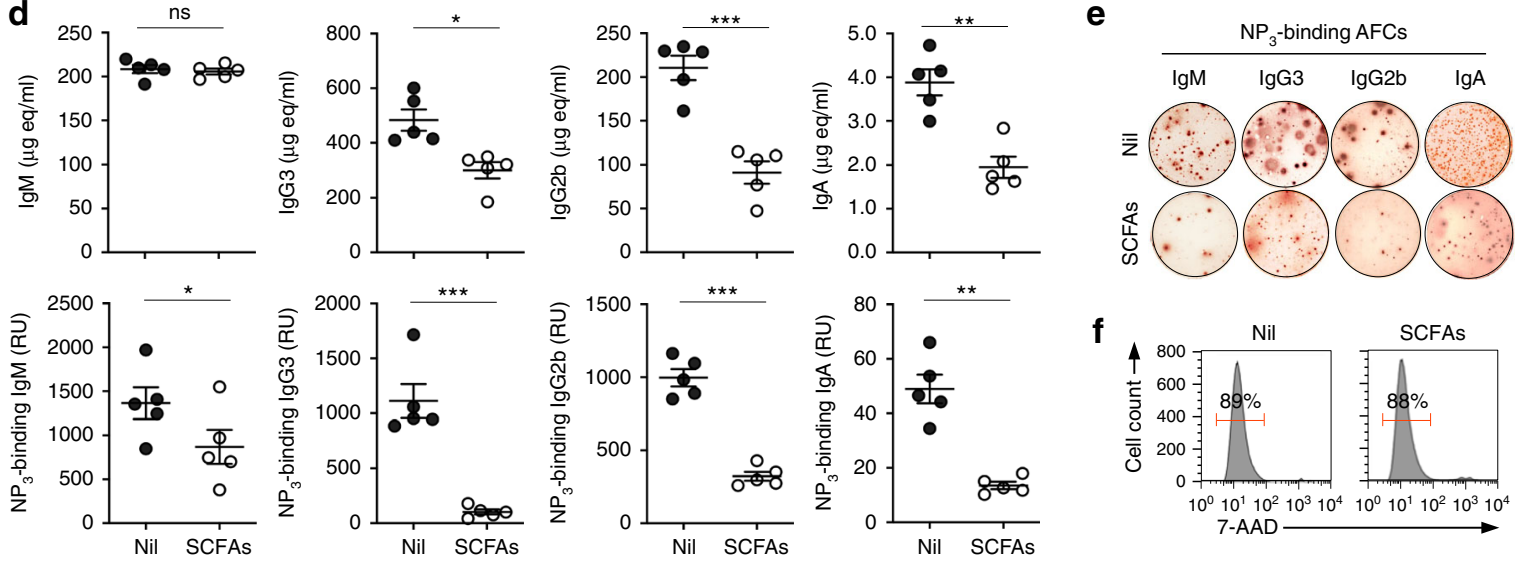

g
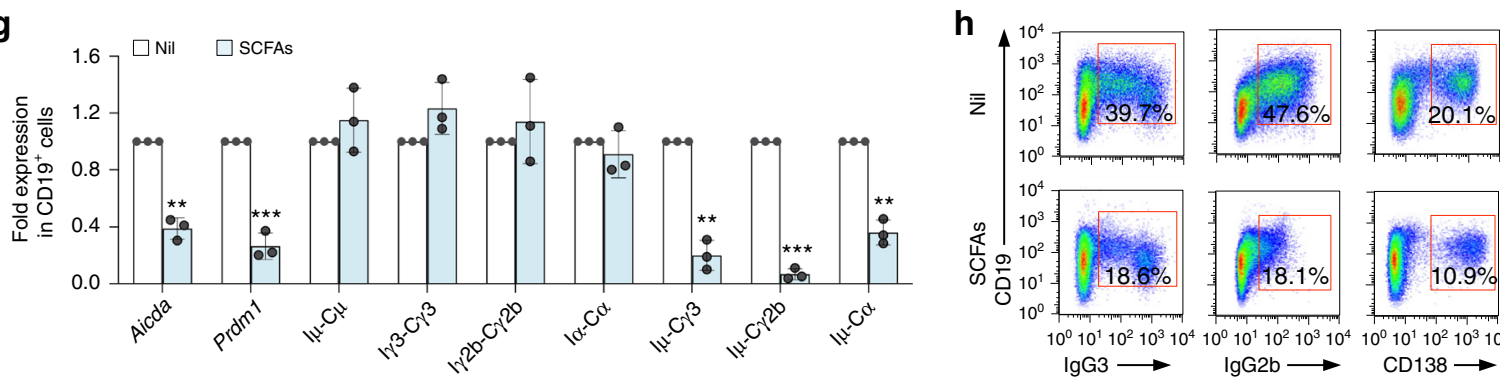

i

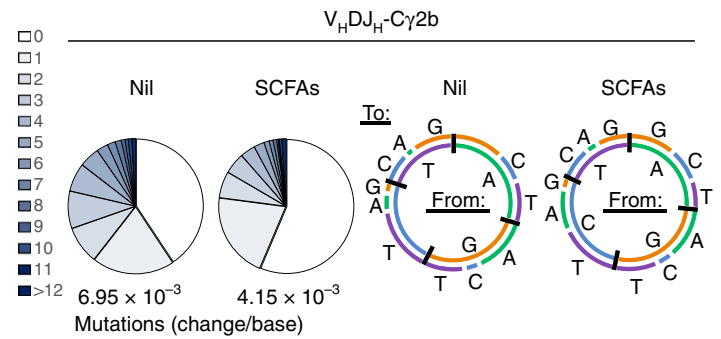

viability or proliferation. This was concomitant with downregulation of AICDA and PRDM1 transcripts, and increased germline I $\gamma 1-C \gamma 1$, I $\alpha-C \alpha$, and I $\varepsilon$-C $\varepsilon$ transcripts, likely due to the HDAC inhibitory activity of butyrate and propionate (Fig. 6a-e; Supplementary Fig. 7d). Thus, SCFAs directly impact mouse and human B cells to decrease Aicda/AICDA and Prdm1/PRDM1 expression, thereby reducing in a dose-dependent fashion CSR to IgG, IgA, and IgE as well as plasma cell differentiation.
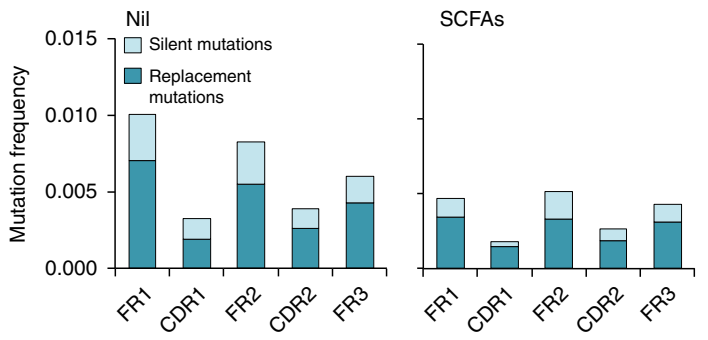

SCFAs dampen Aicda/Prdm1 through HDAC inhibitory activity. Butyrate and propionate can exert their activity by triggering cell signaling through G-protein-coupled receptors (GPRs), by functioning as energy substrate or by directly inhibiting HDACs, thereby modulating gene expression. None of the major SCFA receptors (Gpr43, Gpr41, Gpr109a, or OLFR78) were expressed on the surface of human resting or activated $\mathrm{B}$ cells; and only Gpr43 is expressed on activated mouse B cells 
Fig. 4 Dose-dependent and B-cell-intrinsic modulation of Aicda and Prdm1 expression, CSR, SHM and plasma cell differentiation by SCFAs in vivo. a-c C57BL/6 mice on plain water (Nil), SCFAs "lower dose" water ( $\mathrm{pH}=7.4,20 \mathrm{mM}$ sodium butyrate, and 30 mM sodium propionate) or SCFAs "higher dose" water $\left(\mathrm{pH}=7.4,20 \mathrm{mg} \mathrm{ml}^{-1}\right.$ tributyrin emulsion, $140 \mathrm{mM}$ sodium butyrate and $150 \mathrm{mM}$ sodium propionate, SCFAs higher dose. The SCFAs water is referred here as SCFAs "higher dose" as opposed to the "lower dose" used in these experiments for the sake of clarify) were i.p. injected with NP-LPS. a Total and $\mathrm{NP}_{3}$-binding IgM, IgG2b, and IgG3 induced by low dose of SCFAs, as measured by ELISA. Each symbol represents an individual mouse ( $n=4-5$ per group, pooled from two experiments). Bars represent mean \pm SD. b AID and Blimp1 expression in spleen B cells from the same mice, as analyzed by intracellular staining followed flow cytometry. $\mathbf{c l g G 3}{ }^{+}, \operatorname{lgG} 2 b^{+}$B cells, and CD19low $C D 138^{+}$plasmablasts/plasma cells in the spleen, as analyzed by flow cytometry. Data in $\mathbf{b}$ and $\mathbf{c}$ are representative of three independent experiments. $\mathbf{d}-\mathbf{i} \mathrm{NSG} / \mathrm{B}$ mice on plain water or SCFAs water (pH $=7.4,20 \mathrm{mg} \mathrm{ml}^{-1}$ tributyrin emulsion, $140 \mathrm{mM}$ sodium butyrate, and $150 \mathrm{mM}$ sodium propionate) were injected with NP-LPS. $\mathbf{d}$ Titers of total and NP -binding serum IgM, $\operatorname{lgG} 3$, IgG2b, and IgA, as analyzed by ELISA. Each symbol represents an individual mouse ( $n=5$ per group from one experiments). e $\mathrm{NP}_{3}$-binding $\operatorname{lgM}$, IgG3, IgG2b, and IgA AFCs in spleen as analyzed by ELISPOT. f Viable (7-AAD ${ }^{-}$) spleen CD19+ B cells as analyzed by flow cytometry. $\mathbf{g}$ Aicda, Prdm1, germline $\mathrm{I}_{\mathrm{H}}-\mathrm{C}_{\mathrm{H}}$, and post-recombination $\mathrm{I} \mu-\mathrm{C}_{\mathrm{H}}$ transcripts, as analyzed by qRT-PCR and normalized to Gapdh. Data are ratios to $\mathrm{B}$ cells cultured with nil (set as $1 ;$ means \pm SEM of three independent experiments). $\mathbf{h}$ Proportion of $\operatorname{lgG} 3^{+}$and $\mathrm{IgG} 2 \mathrm{~b}^{+} \mathrm{B}$ cells, and $\mathrm{CD}_{138^{+}}$plasmablasts/plasma cells in the spleen, as analyzed by flow cytometry. $\mathbf{i}$ Somatic point mutations in the $\mathrm{V}_{\mathrm{H}}$ region of $\mathrm{V}_{\mathrm{H}} \mathrm{D} \mathrm{J}_{\mathrm{H}}-\mathrm{C} \gamma 2 \mathrm{~b}$ transcripts. Mutations are in pooled sequences from two out of five mice per group. Pie charts depict the proportions of sequences that carry different numbers of point mutations; listed below the pie charts is the overall mutation frequency. Donut charts depict the spectrum of point mutations. Histograms depict frequencies of silent and replacement mutations in FR and CDR regions. ${ }^{\star} p<0.05,{ }^{\star \star} p<0.01,{ }^{\star \star \star} p<0.001$, ns: not significant (unpaired $t$ test). The source data are provided in Source Data file.

(Supplementary Fig. 10a, b). This together with the failure of Gpr43 blocker GPLG0974 to interfere with butyrate- and propionate-mediated inhibition of CSR (Fig. 7a, b) demonstrated that SCFAs do not exert their activity on B cells by triggering cell signaling through GPRs. To address whether SCFAs function as energy substrate or HDAC inhibitors to modulate Aicda and $\operatorname{Prdm} 1$ expression, CSR, and plasma cell differentiation, we stimulated mouse B cells with LPS plus IL- 4 in the presence of nil, butyrate, propionate, long-chain fatty acid palmitate, or the nonSCFA HDAC inhibitors SAHA and TSA. Butyrate and propionate can function as an energy substrate by entering the tricarboxylic acid (TCA) cycle after breaking down to acetyl-CoA through $\beta$-oxidation. Palmitate can also function as an energy substrate $^{44}$, after breaking down to acetyl-CoA, but cannot signal through GPR receptors or function as HDI. SAHA can only function as HDI, as it does neither enter the TCA cycle nor does it signal through GPRs. Consistent with the contention that butyrate and propionate inhibit Aicda and Prdm1 expression through their HDAC inhibitory activity only, SAHA and TSA but not palmitate mimicked the activity of these SCFAs on Aicda and $\operatorname{Prdm} 1$ expression, thereby reducing CSR and plasma cell differentiation (Fig. 7c-f; Supplementary Fig. 11a, b). Like butyrate and propionate, SAHA and TSA increased germline $\mathrm{I}_{\mathrm{H}}-\mathrm{C}_{\mathrm{H}}$ transcripts, and at low concentrations (SAHA, $<0.050 \mu \mathrm{M}$; TSA, < $0.0025 \mu \mathrm{M})$ moderately increased Aicda and CSR. Like butyrate and propionate, these non-SCFA HDAC inhibitors reduced Aicda and $\operatorname{Prdm} 1$ expression, CSR, and plasma cell differentiation in a dose-dependent fashion.

Fluorometric analysis of HDAC activity in B cells stimulated with LPS plus IL-4 and in the presence of butyrate or propionate for 48 or $72 \mathrm{~h}$ confirmed the HDAC inhibitory activity of these SCFAs in B cells (Supplementary Fig. 8b), which led to increased acetylation of histone $\mathrm{H} 3$ in Aicda promoter, Aicda regulatory region 4, $\operatorname{Prdm} 1$ promoter, as well as $\mathrm{I} \gamma 1, \mathrm{I} \gamma 3$, and Ia promoters (Supplementary Fig. 8c). The dispensability of butyrate and propionate as energy substrates was further emphasized by the lack of impact of etomoxir on the inhibition of CSR and plasma cell differentiation by these SCFAs (Supplementary Fig. 10c-e) etomoxir prevents the formation of acylcarnitine, which is necessary for fatty acyl-chains transport from the mitochondria into the intermembrane space, thereby inhibiting fatty acid $\beta$ oxidation, which is required for butyrate-mediated energy metabolism and production of $\mathrm{ATP}^{44}$. Thus, SCFAs downregulate B cell Aicda and Prdm1 through their HDAC inhibitory activity.
SCFAs increase select miRNAs targeting Aicda or Prdm1 3'UTR. Acting as HDIs, butyrate and propionate increased overall histone (H3K9) acetylation in stimulated primary human and mouse B cells and CH12F3 B cells induced to undergo CSR and plasma cell differentiation, as well as and in B cells isolated from mouse on SCFAs water (Fig. 8a, b). As we have shown, HDIs, such as VPA, upregulate select miRNAs that target Aicda and Prdm1 transcripts in B cells to silence the expression of these genes $^{8,33}$. We hypothesized that SCFAs inhibit Aicda and Prdm1 expression in a similar fashion. Indeed, butyrate selectively increased transcription of miR-155, miR-181b, and miR-26a, which target Aicda mRNA-3'UTR, concomitant with that of miR30c, miR-182, miR-200c, and let-7a, which target Prdm1 mRNA3'UTR, and miR-125a, which targets both Aicda and Prdm1 mRNA-3'UTRs, in mouse B cells (Fig. 8c; Supplementary Fig. 12). Increased transcription of these miRNAs reflected butyrate-mediated inhibition of the HDACs acting on the respective miRNA host genes (HGs), leading to hyperacetylation of miR155HG, miR-181bHG, miR-26aHG, and miR-125aHG (encoding miRNAs targeting Aicda $3^{\prime} \mathrm{UTR}$ ) as well as miR30cHG, miR-182HG, miR-200cHG, and let-7aHG (encoding miRNAs targeting Prdm1 3'UTR) (Fig. 8d). The selectivity of butyrate in upregulating miRNAs that target Aicda/AICDA and Prdm1/ PRDM1 was emphasized by the failure of this SCFA to upregulate B-cell transcription of miR-19a/b, miR-20a, miR-25, miR27b, miR24, miR-106, miR-186, and miR-206, which are not known to regulate Aicda or Prdm1 (Fig. 8c). In human B cells, butyrate selectively increased transcription of miR-155-5p, miR-26a-5p, and miR-125a-5p, which target $A I C D A-3^{\prime} \mathrm{UTR}$, together with transcription of miR-182-5p, miR-30d-3p, miR-200c-3p, which target PRDM1-3'UTR (Fig. 9a-d).

To demonstrate that SCFAs-downregulation of AID and Blimp1 is mediated by upregulation of miRNAs targeting Aicda and Prdm1 mRNA-3' UTRs, we cloned wild-type and mutant (mut) sequences of Aicda and Prdm1 3'UTRs (mut 3'UTRs were constructed by mutation of the target sites of miR-26a, miR-125a, and miR-155 in Aicda mRNA-3'UTR or target sites of miR-125a, miR-30c, and miR-182 in Prdm1 mRNA-3'UTR) into pMIRREPORT luciferase reporter vectors (Fig. 8e). These were used to transfect mouse $\mathrm{CH} 12 \mathrm{~F} 3 \mathrm{~B}$ cells, which were then induced to undergo CSR at a high rate. Like in primary B cells, butyrate upregulated miR-26a, miR-125a, miR-155, miR-125a, miR-30c, and miR-182 expression and reduced CSR in CH12F3 B cells stimulated with CD154 plus TGF- $\beta$ and IL-4 (Fig. 8f, g). The ability of these butyrate-induced-miRNAs to repress luciferase 
a

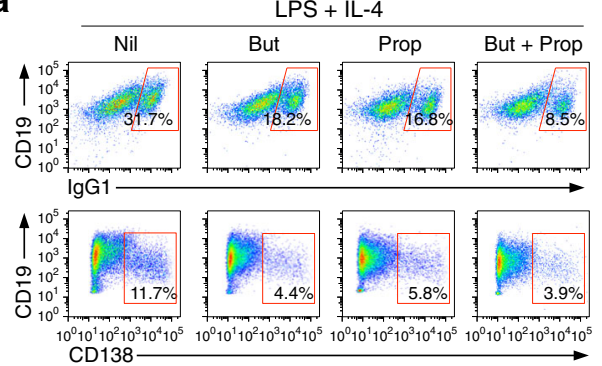

C

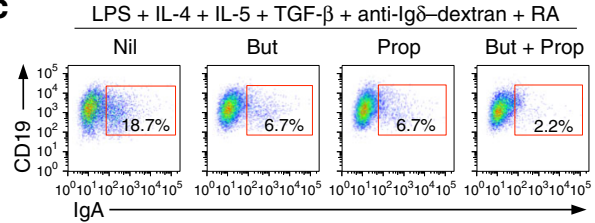

e

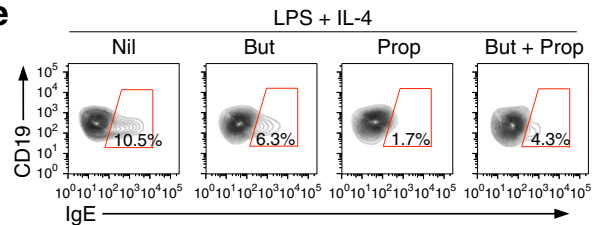

$\mathbf{f}$

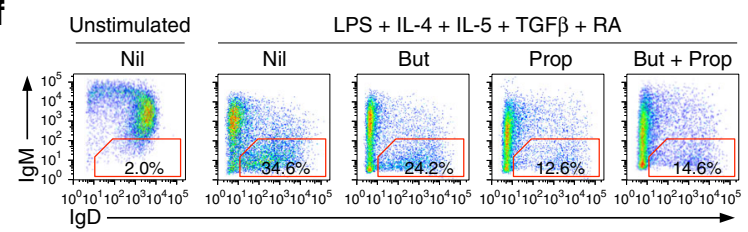

K Isotype control

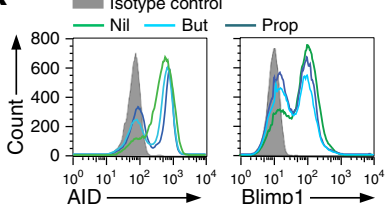

g

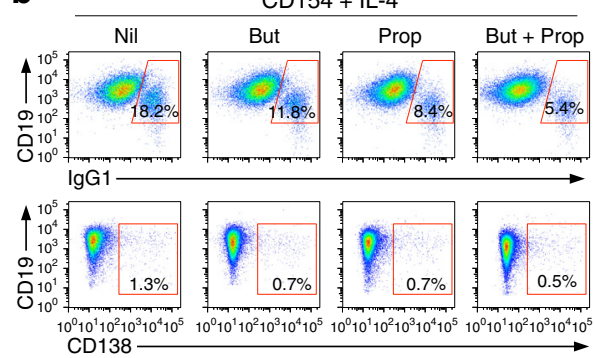

d $\quad \mathrm{CD} 154+\mathrm{IL}-4+\mathrm{IL}-5+\mathrm{TGF}-\beta+$ anti-lg $\delta-$ dextran + RA

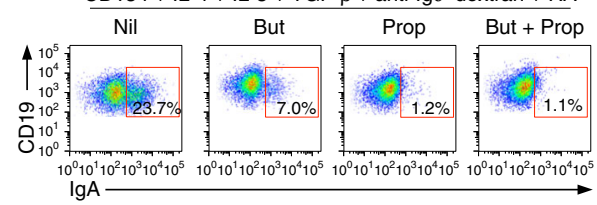

i $\square$ Nil $\square$ But $\square$ Prop $\square$ But + Prop

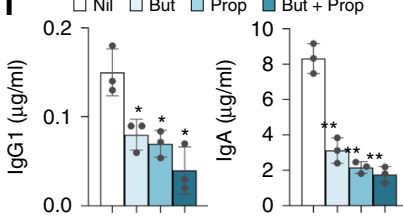

I

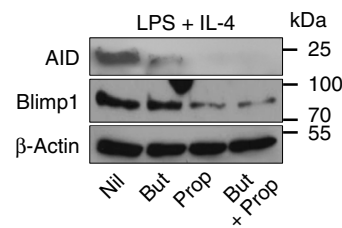

j

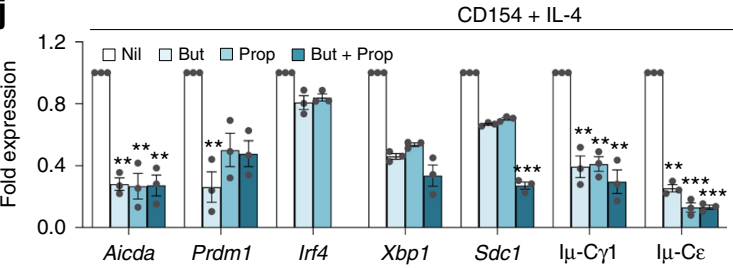

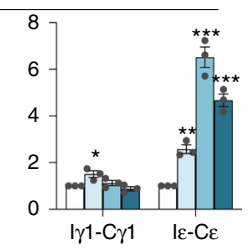

CD154 + IL-4 + IL-5 + TGF- $\beta+$ anti-lg $\delta-$ dextran + RA

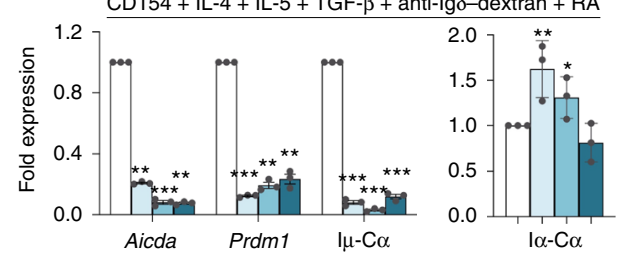

Fig. 5 SCFAs inhibit Aicda and Prdm1 expression, and reduce CSR and plasma cell differentiation in mouse B cells. a-f Mouse B cells were stimulated in the presence of Nil, butyrate $(500 \mu \mathrm{M}$, But), propionate $(2000 \mu \mathrm{M}$, Prop), or butyrate $(500 \mu \mathrm{M})$ plus propionate $(2000 \mu \mathrm{M})$. Proportions of surface CD19 $+\operatorname{lgG1}{ }^{+} \mathrm{B}$ cells and $\mathrm{CD138}+$ plasmablasts/plasma cells $(\mathbf{a}, \mathbf{b})$, surface CD19+ IgA+ B cells (c, d), intracellular CD19+ IgE ${ }^{+}$B cells (e), and surface CD19+ IgM- IgD + B cells (f) as analyzed by flow cytometry $96 \mathrm{~h}$ after stimulation. $\mathbf{g}$, $\mathbf{h}$ CD19+ B cells were labeled with CFSE and stimulated for $96 \mathrm{~h}$ with LPS plus IL-4 in the presence of nil, butyrate $(500 \mu \mathrm{M})$, or propionate $(2000 \mu \mathrm{M})$. CFSE intensity and surface IgG1 expression as analyzed by flow cytometry. Progressive left shift of fluorescence intensity indicates CD19+ B-cell division. Data are representative of three independent experiments yielding comparable results $(\mathbf{g})$. Proportion of surface $\operatorname{lgG} 1^{+}$B cells at each cell division. Data are mean and SE from three independent experiments (h). $\mathbf{i}$ Titers of $\operatorname{lgG1}$ and IgA in culture fluids as analyzed by ELISA. Data are from three independent experiments (mean and SE). j Aicda, Prdm1, Irf4, Xbp1, Sdc1, postrecombination $|\mu-C \gamma 1,| \mu-C \varepsilon$, and $\mid \mu-C \alpha$ transcripts as well as germline $|\gamma 1-C \gamma 1,| \varepsilon-C \varepsilon$, and $\mid \alpha-C \alpha$ transcripts in B cells stimulated with LPS plus IL-4, or CD154 plus IL-4, IL-5, TGF- $\beta$, anti- $\delta$ mAb-dextran in the presence of butyrate, propionate, or butyrate plus propionate for $60 \mathrm{~h}$, as analyzed by qRT-PCR and normalized to Gapdh transcripts. Data are ratios to stimulated B cells cultured with nil (set as 1; means \pm SEM of three independent experiments). $\mathbf{k}$, I B cells were stimulated with LPS plus IL-4 in the presence of nil, butyrate, propionate, or butyrate plus propionate for $72 \mathrm{~h}$. The B-cell expression of AID and Blimp1 as determined by intracellular staining and flow cytometry ( $\mathbf{k}$ ). AID, Blimp1, and $\beta$-Actin proteins, as detected by immunoblotting (I). Data are one representative of three independent experiments yielding comparable results. ${ }^{\star} p<0.05,{ }^{\star \star} p<0.01,{ }^{\star \star \star} p<0.001$ (unpaired $t$ test). The source data are provided in Source Data file.

activity was then analyzed using reporter constructs-containing wild-type or mutant Aicda and Prdm1-3'UTRs. Butyrate reduced the luciferase reporter activity in $\mathrm{CH} 12 \mathrm{~F} 3 \mathrm{~B}$ cells transfected by wild-type, but not mutant reporter constructs (Fig. 8h). Thus, in B cells, butyrate inhibits histone deacetylation of the host genes of select miRNAs, which target Aicda and Prdm1 mRNAs, thereby reducing AID and Blimp1 expression.
SCFAs inhibit autoantibodies and autoimmunity in lupusprone mice. To address the impact of SCFAs on the autoantibody response, we fed four female lupus-prone MRL/Fas ${ }^{l p r / l p r}$ mice SCFAs water and four MRL/Fas ${ }^{p r / l p r}$ mice plain water, starting at 5 weeks of age. We also fed five female lupus-prone NZB/W F1 mice SCFAs water and five NZB/W F1 mice plain water, starting at 14 weeks of age. These ages precede the initial clinical 
a
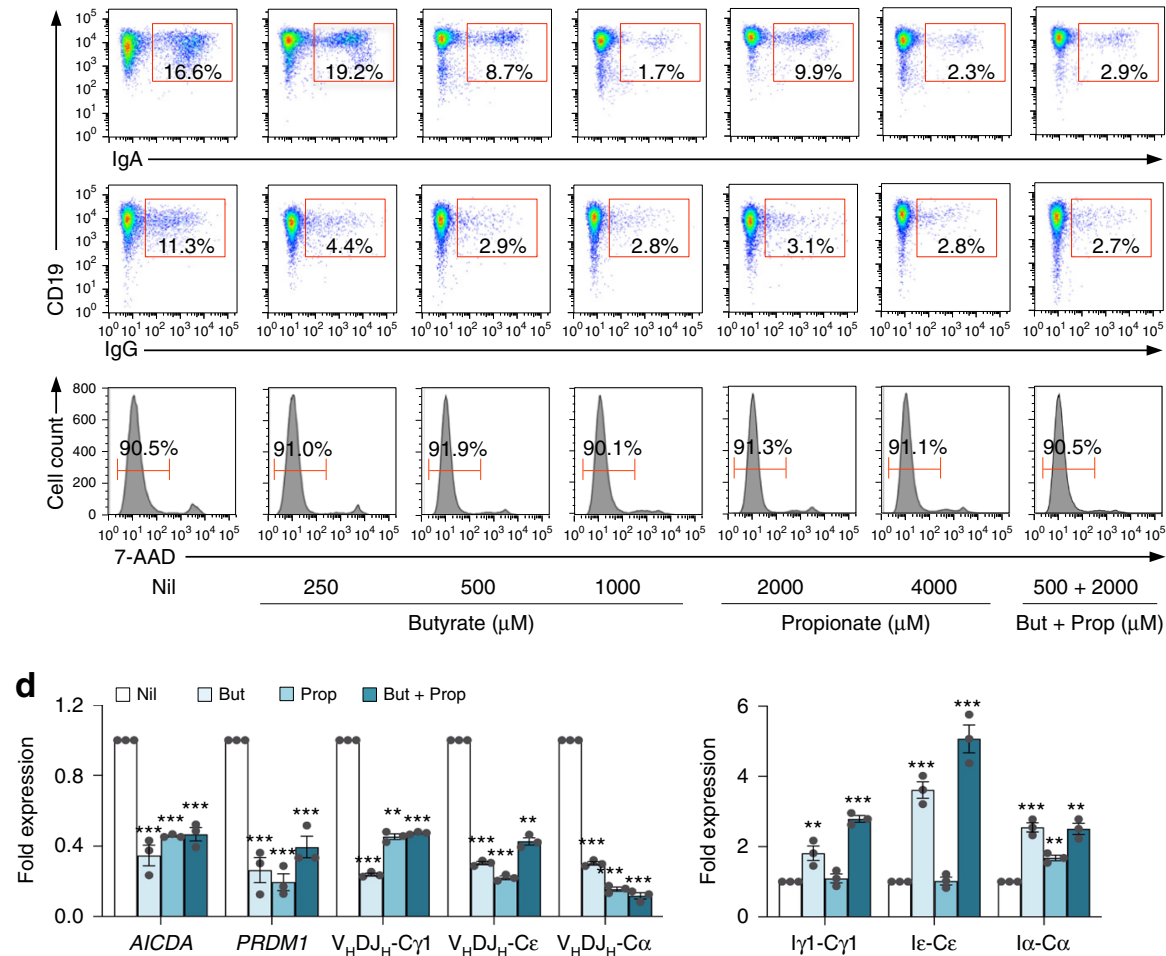

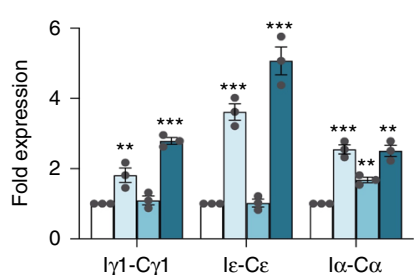

b

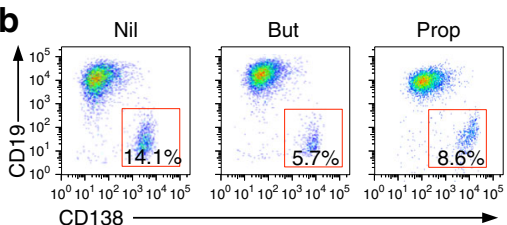

C
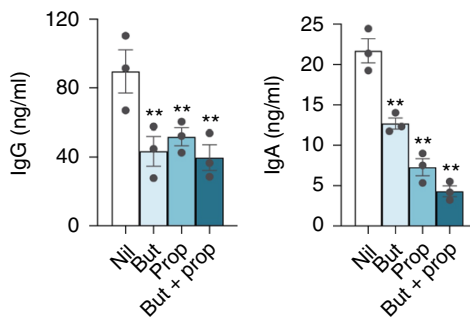

Fig. 6 Butyrate and propionate inhibit AICDA and PRDM1 expression, and reduce CSR and plasma cell differentiation in human B cells. a Human B cells purified from PBMCs of healthy subjects were stimulated with CD154 plus IL-4 and IL-21, in the presence of nil, butyrate (250, 500, or 1000 $\mu \mathrm{M})$, propionate $(2000$ or $4000 \mu \mathrm{M})$, or butyrate $(500 \mu \mathrm{M})$ plus propionate $(2000 \mu \mathrm{M})$. The proportions of $\mathrm{CD}_{19}{ }^{+} \operatorname{lgA} \mathrm{A}^{+}$and $\mathrm{CD} 19^{+}$IgG ${ }^{+}$as well as viable $(7-$ $\left.\mathrm{AAD}^{-}\right) \mathrm{CD}^{+}{ }^{+} \mathrm{B}$ cells were analyzed $120 \mathrm{~h}$ post stimulation by flow cytometry. Data are representative of three independent experiments yielding comparable results. b-d Human B cells were stimulated with CD154 plus IL-4 and IL-21, in the presence of nil, butyrate (500 $\mu \mathrm{M})$, propionate (2000 $\mu \mathrm{M})$, or butyrate $(500 \mu \mathrm{M})$ plus propionate $(2000 \mu \mathrm{M})$. CD19lo CD138+ plasma cells were analyzed $120 \mathrm{~h}$ post stimulation by flow cytometry (b). IgG and lgA titers in culture fluids of these $B$ cells were analyzed $120 \mathrm{~h}$ post stimulation by ELISA. Data are from three independent experiments (mean and SE) (c). Expression of $A I C D A$ and $P R D M 1$, germline $\mid \gamma 1-C \gamma 1$, $\mid \alpha-C \alpha$, and $l \varepsilon-C \varepsilon$, as well as mature $V_{H} D J_{H^{-}} C \gamma 1, V_{H} D J_{H^{-}}-C \varepsilon$, and $V_{H} D J_{H^{-}}-C \alpha$ transcripts were analyzed 72 $\mathrm{h}$ post stimulation by $\mathrm{qRT}-\mathrm{PCR}$ and normalized to the expression of HRPT. Data are ratios to stimulated $\mathrm{B}$ cells cultured with nil (set as $1 ;$ means $\pm \mathrm{SEM}$ of three independent experiments) (d). e Human B cells were labeled with CFSE and stimulated with CD154 plus IL-4 and IL-21 in the presence of nil, butyrate $(500 \mu \mathrm{M})$, or propionate $(2000 \mu \mathrm{M})$ for $96 \mathrm{~h}$. CFSE intensity were analyzed by flow cytometry. Progressive left shift of fluorescence intensity indicates CD19+ B-cell division. Data are representative of three independent experiments yielding comparable results. ${ }^{\star \star} p<0.01,{ }^{\star \star \star} p<0.001$ (unpaired $t$ test). The source data are provided in Source Data file.

manifestations of lupus. At 12 or 26 weeks of age, respectively,

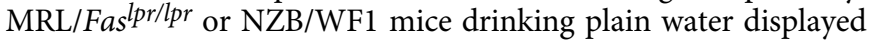
high titers of IgM autoantibodies to dsDNA and histone, IgG1 and IgG2a autoantibodies to dsDNA, RNP/Sm, RNA, histone, and nuclei, as well as increased B cell AID and Blimp1 expression (Fig. 10a-f; Supplementary Fig. 13a, b). They also developed $\operatorname{IgG} 1^{+}, \operatorname{IgG} 2 \mathrm{a}^{+}, \operatorname{IgG} 2 \mathrm{~b}^{+}$, and $\mathrm{IgG}^{+} \mathrm{B}$ cells, $\mathrm{CD} 138^{+} \mathrm{IgG1}{ }^{+}$, $\mathrm{CD}_{138}{ }^{+} \mathrm{IgG}_{2} \mathrm{a}^{+}, \mathrm{CD}_{138^{+}} \mathrm{IgG} \mathrm{b}^{+}$, and $\mathrm{CD} 138^{+} \mathrm{IgG}^{+}$plasmablasts/plasma cells, skin lesions (MRL/Fas ${ }^{l p r / p r}$ ), IgG1/IgG2 kidney deposition and glomerular sclerosis. By contrast, the MRL/ Fas ${ }^{l p / / p r}$ and NZB/W F1 mice drinking SCFAs water displayed significantly lower titers of IgG1 and IgG2a (not IgM) autoantibodies to dsDNA, RNP/Sm, anti-RNA, histone, and nuclei, as well as reduced B cell AID and Blimp1 expression (Fig. 10a-f; Supplementary Fig. 13c-f, 7). They also displayed reduced numbers of $\mathrm{IgG1}^{+}, \operatorname{IgG} 2 \mathrm{a}^{+}, \mathrm{IgG}_{2} \mathrm{~b}^{+}$, and $\mathrm{IgG} 3^{+} \mathrm{B}$ cells as well as $\mathrm{CD}_{138^{+}} \mathrm{IgG}^{+}, \mathrm{CD} 138^{+} \mathrm{IgG}_{2} \mathrm{a}^{+}, \mathrm{CD} 138^{+} \mathrm{IgG} 2 \mathrm{~b}^{+}$, and $\mathrm{CD} 138$ ${ }^{+} \mathrm{IgG3}^{+}$plasmablasts/plasma cells, and virtually no skin lesion. Finally, they showed no IgG1/IgG2a kidney deposition or glomerular damage. Thus, in lupus-prone mice, SCFAs dampen B cell AID and Blimp1 expression, plasma cell differentiation, systemic class-switched autoantibodies, and abolish lupus skin lesions and kidney pathology.

\section{Discussion}

SCFAs derived from fermentation of resistant fibers by gut microbiota can impact functions of immune cells, including $\mathrm{T}$ cells, DCs, and macrophages $1,3,13,20,30,31$, and through these cells might impact antibody responses $1,4,9,10,20,27,40,45$. Here, we showed that butyrate and propionate act directly and, in a dosedependent fashion, over a broad physiological range, on human and mouse B cells to downregulate AID and Blimp expression, thereby restricting CSR (to $\operatorname{IgD}, \operatorname{IgG}, \operatorname{IgA}$, and $\operatorname{IgE}$ )/SHM and plasma cell differentiation through epigenetic modulation (expression of select miRNAs by histone acetylation of the related host genes) of AICDA/Aicda and PRDM1/Prdm1 transcription (Supplementary Fig. 14). The significance of this SCFAs epigenetic impact on $\mathrm{B}$ cells was heightened by butyrate and propionate curtailing CSR/SHM and plasma cell differentiation in T-dependent and T-independent antibody responses to OVA in C57BL/6 mice, to NP in NP-CGG- and NP-LPS-injected C57BL/ 6 mice and NP-LPS-injected T-cell knockout $\left(\mathrm{Tcr} \beta^{-/-} \mathrm{Tcr} \delta^{-/-}\right)$ mice, as well as in NP-LPS-injected NSG/B mice. The direct activity of SCFAs on B cells adds to the reported SCFA-mediated modulation of other immune cells, such as $\mathrm{T}$ cells, particularly Tregs, DCs, ILC2, ILC3, and macrophages $2,3,11,15,19,20,24,26-29,46$, and would critically contribute to maintaining a steady state 
a

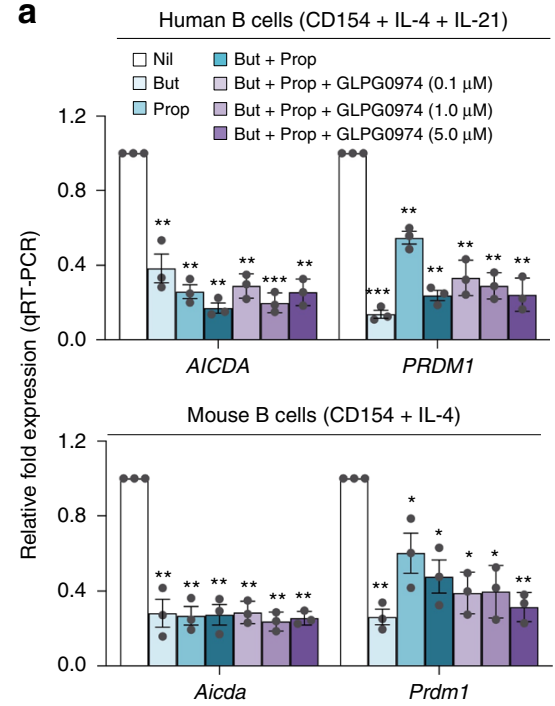

C

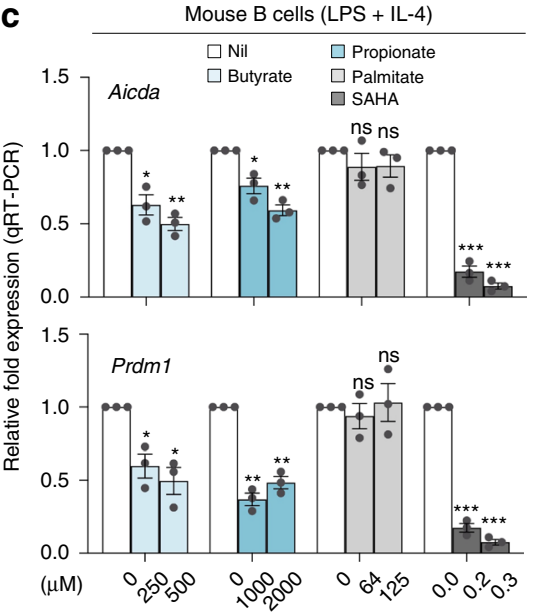

b

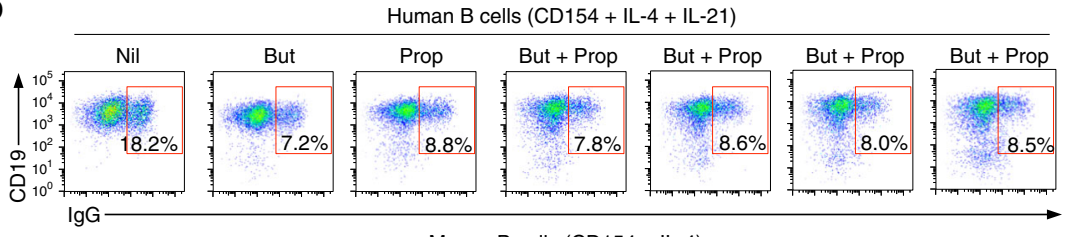

Mouse B cells (CD154 + IL-4)

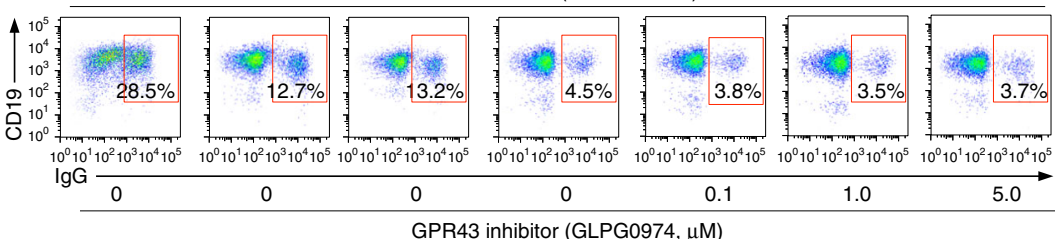

d

Mouse B cells (LPS + IL-4)

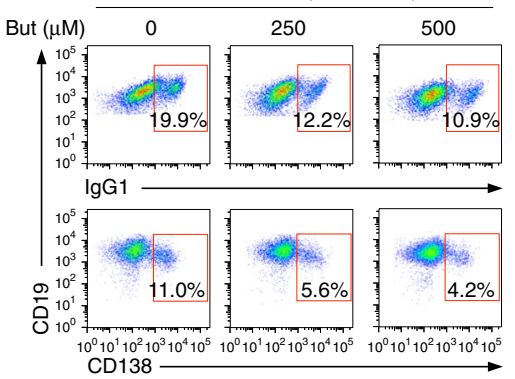

e Palmitate $(\mu \mathrm{M}) \quad 0 \quad 64 \quad 125$
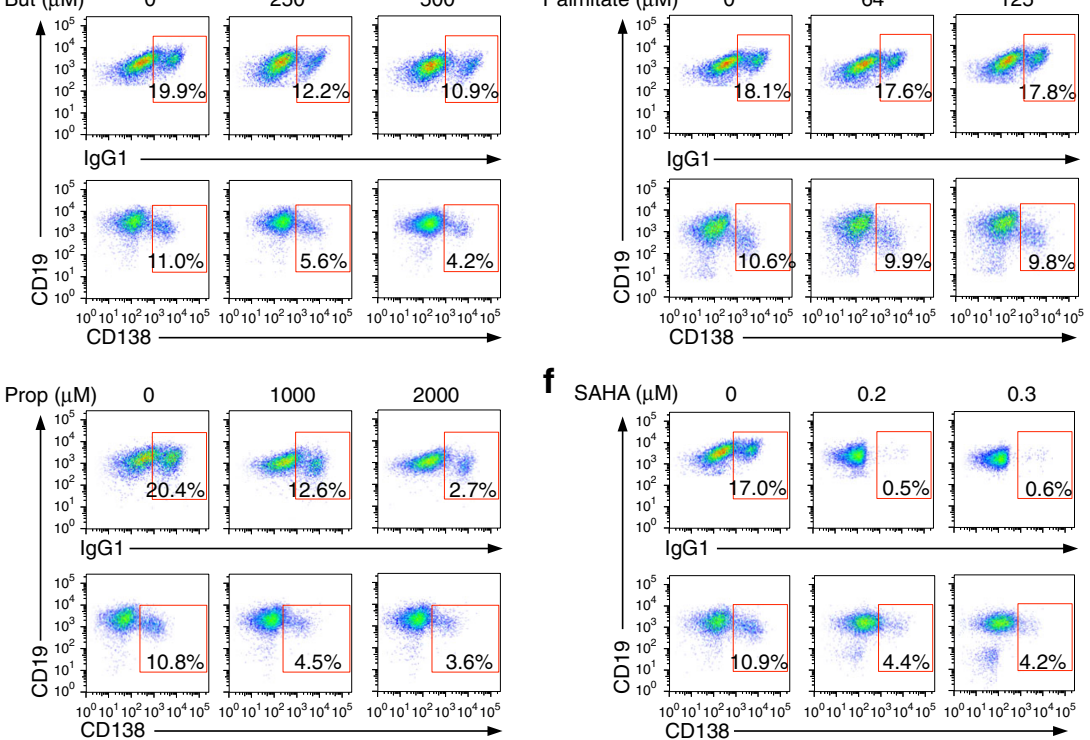

f

$$
\text { CD138 }
$$

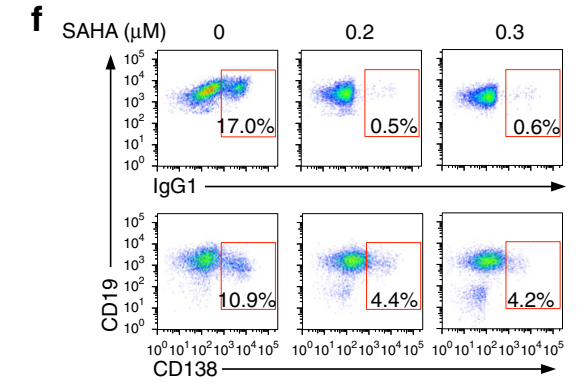

Fig. 7 SCFAs inhibit AICDA/Aicda and PRDM1/Prdm1 expression, CSR, and plasma cell differentiation through their HDAC inhibitory activity. a, $b$ Human and mouse B cells were stimulated with CD154 plus IL-4 and IL-21, or CD154 plus IL-4, respectively, in the presence of nil, butyrate (500 $\mu$ M), propionate $(2000 \mu \mathrm{M})$, butyrate $(500 \mu \mathrm{M})$ plus propionate $(2000 \mu \mathrm{M})$ alone, or butyrate $(2000 \mu \mathrm{M})$ plus propionate $(2000 \mu \mathrm{M})$ together with increasing doses of GPR43 inhibitor GLPG0974. Human B cell AICDA and PRDM1 transcripts as well as mouse B cell Aicda and Prdm1 transcripts were analyzed $72 \mathrm{~h}$ post stimulation by qRT-PCR and normalized to HRPT and Gapdh expression, respectively. Data are ratios to stimulated B cells cultured with nil (set as 1; means \pm SEM of three independent experiments) (a). Proportion of $\mathrm{CD} 19+\operatorname{lgG}+\mathrm{B}$ cells were analyzed $120 \mathrm{~h}$ post stimulation by flow cytometry. Data are representative of three independent experiments yielding comparable results (b). c-f Mouse B cells were stimulated with LPS plus IL-4, in the presence of increasing doses of butyrate, propionate, palmitate, and SAHA. Expression of Aicda and Prdm1 transcripts were analyzed $72 \mathrm{~h}$ post stimulation by qRT-PCR and normalized to Gapdh expression. Data are ratios to stimulated B cells cultured with nil (set as 1; means \pm SEM of three independent experiments) (c). The proportion of $\mathrm{CD} 19^{+} \mathrm{lgG} 1^{+} \mathrm{B}$ cells and $\mathrm{CD} 138^{+}$plasmablasts/plasma cells were analyzed $120 \mathrm{~h}$ post stimulation by flow cytometry. Data are representative of three independent experiments yielding comparable results (d-f). ${ }^{\star} p<0.05,{ }^{\star \star} p<0.01,{ }^{\star \star \star} p<0.001$ (unpaired $t$ test). The source data are provided in Source Data file.

balance between tolerance to commensal bacteria and immunity to pathogens, and, therefore, contributing to gut and systemic immune homeostasis.

Fermentation of dietary fibers by gut microbiota occurs primarily in distal jejunum, cecum, and proximal-medium colon. Butyrate is the preferred energy source for colonocytes and is consumed locally, before being resorbed, together with propionate and acetate throughout the colon, drained into the mesenteric veins and the portal vein to the liver, and, through the liver, to the rest of the body. Active transporters, such as the $\mathrm{Na}^{+}$-coupled SLC5a transporter and monocarboxylate transporter 1 (MCT1/SLC16a1), transport SCFA molecules across the cell membrane from an extracellular milieu of low SCFA concentration, such as in the circulatory torrent, into the cell, leading to higher intracellular SCFA concentrations. In this way, SCFAs accumulate in colon tissue, MLNs, and spleen at higher concentrations, higher enough for example to limit AID expression in inflamed colon mucosa, in which AID is induced by proinflammatory cytokines ${ }^{47}$. The SCFAs concentrations we used in vitro to inhibit AID and Blimp1 expression, CSR, and plasma cell differentiation reflected those in the spleen and MLNs of mice fed a regular chow (fiber diet), further emphasizing the physiological relevance of our findings. In our mice, butyrate and propionate, whether derived from gut fiber fermentation and/or SCFAs water, impacted B cells and antibody responses at both intestinal and systemic level. This resulting from systemic SCFAs impact on peripheral B cells and decreased input into the periphery of fewer class-switched AFCs, particularly $\operatorname{IgA}^{+} \mathrm{B}$ cells, from the intestine due to high local SCFAs levels. 
a

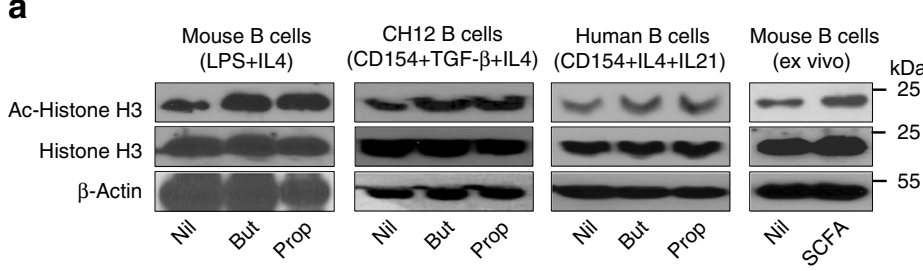

C

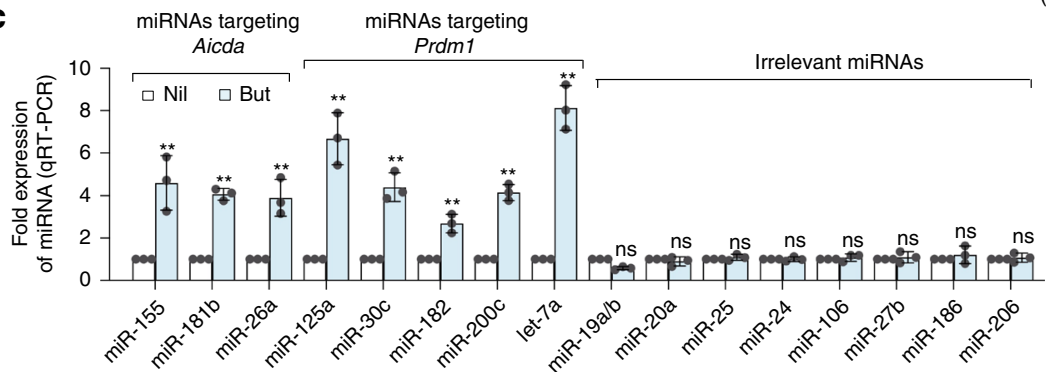

d

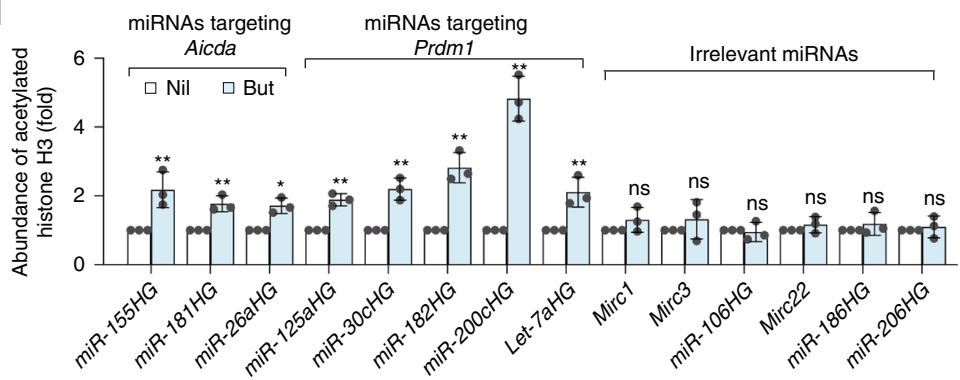

b.

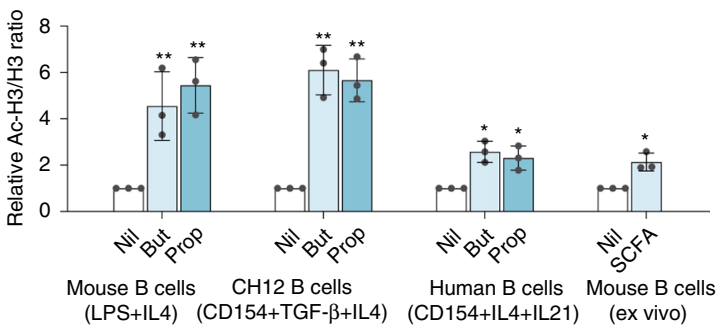

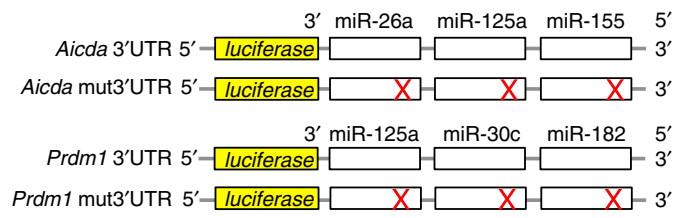

g

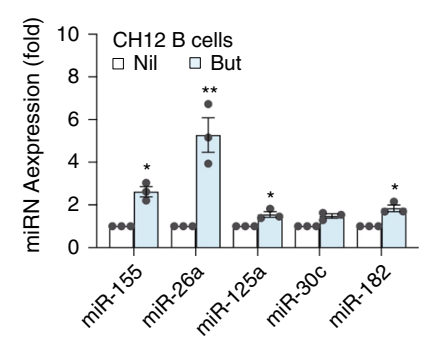

h

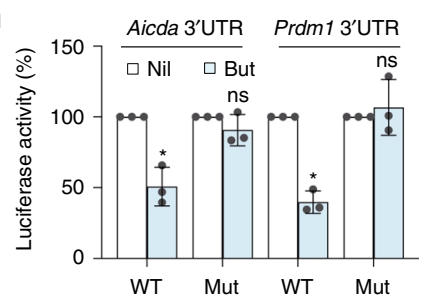

Fig. 8 SCFAs increase expression of Aicda- and Prdm1-targeting miRNAs by enhancing histone acetylation of related miRNA host genes. a Primary mouse B cells, CH12F3 B cells, and human B cells were stimulated with indicated stimuli for $60 \mathrm{~h}$ in the presence of nil, butyrate ( $500 \mu \mathrm{M}$ ), or propionate $(2000 \mu \mathrm{M})$. Ex vivo B cells were isolated from mice injected with NP-LPS and on plain water or SCFA water for 21 days. Acetylated-histone H3 (H3K9ac), histone $\mathrm{H} 3$, and $\beta$-actin proteins as detected by immunoblotting. Data are one representative of three independent experiments. b Relative densities of the Ac-histone $\mathrm{H} 3$ bands normalized to histone $\mathrm{H} 3$ and $\beta$-actin levels. c, d B cells stimulated with LPS plus IL- 4 in the presence of nil or butyrate for $60 \mathrm{~h}$. Expression of the Aicda- and Prdm1-targeting miRNAs, and irrelevant miRNAs as analyzed by qRT-PCR (c). Relative abundance of H3K9ac/K14ac in miRNA host genes (HGs) as analyzed by ChIP-qPCR (d). e Schematic diagram of the luciferase reporter constructs-containing 3'UTRs of Aicda and Prdm1 mRNAs and their mutant (mut) counterparts. $\mathbf{f}$ Surface CD19 and IgA on CH12F3 B cells stimulated for $96 \mathrm{~h}$ in the presence of nil, butyrate (500 $\mu \mathrm{M})$, propionate $(2000 \mu \mathrm{M})$, or VPA $(500 \mu \mathrm{M})$ as analyzed by flow cytometry. Data are one representative of 3 independent experiments yielding comparable results. $\mathbf{g}$, miRNA expression in CH12F3 cells stimulated for $24 \mathrm{~h}$ in the presence of nil or butyrate, as analyzed by qRT-PCR. Data in $\mathbf{c}$, $\mathbf{d}$, and $\mathbf{g}$ are ratios to stimulated B cells cultured with nil (set as 1 ; means \pm SEM of three independent experiments). $\mathbf{h}$ Luciferase activity in $\mathrm{CH} 12 \mathrm{~F} 3$ cells transfected with luciferase reporter vectors-containing wild-type or mutated Aicda or Prdm1 3'UTRs after $24 \mathrm{~h}$ treatment with nil or butyrate. Luciferase activity was measured $6 \mathrm{~h}$ after transfection, and normalized relative to luciferase activity in B cells cultured with nil. Data in $\mathbf{h}$ are ratios to transfected B cells cultured with nil (set as $100 \%$; means \pm SEM of three independent experiments). ${ }^{\star} p<0.05$, ${ }^{\star \star} p<0.01$, ns: not significant (unpaired $t$ test). The source data are provided in Source Data file.

In addition to acting as HDIs after entering the cell via membrane diffusion or by monocarboxylate $\mathrm{H}^{+}$- or $\mathrm{K}^{+}$-coupled transporters, SCFAs can function as an energy substrate, to increase oxidative phosphorylation, glycolysis, and fatty acid synthesis. They can also modulate cell functions by binding to cell surface GPRs, such as GPR41, GPR43, GPR109A, or OLFR78, to trigger select signaling pathways, some of which with metabolic reach $^{1,9,48}$. As we show here, GPR41, GPR43, GPR109A, and OLFR78 genes are not expressed or virtually not expressed on human B cells, and only Gpr43 is expressed on mouse B cells. Nevertheless, blocking B cell Gpr43 by GPLG0974 or culturing B cells with acetate, a GPR ligand functioning as an energy substrate but not possessing HDAC inhibitory activity, did not affect butyrate and propionate-mediated modulation of Aicda and $\operatorname{Prdm1}$, CSR, or plasma cell differentiation. This together with the demonstration that etomoxir did not reverse the butyrate and propionate-mediated inhibition of the same processes, further argue against a role of SCFAs as energy substrate in promoting such B-cell processes. Thus, the notion suggested by a recent report $^{12}$ that SCFAs boost IgG and IgA responses functioning as energy substrate is at odds with our exhaustive findings that butyrate and propionate display potent HDAC inhibitory activity 
a
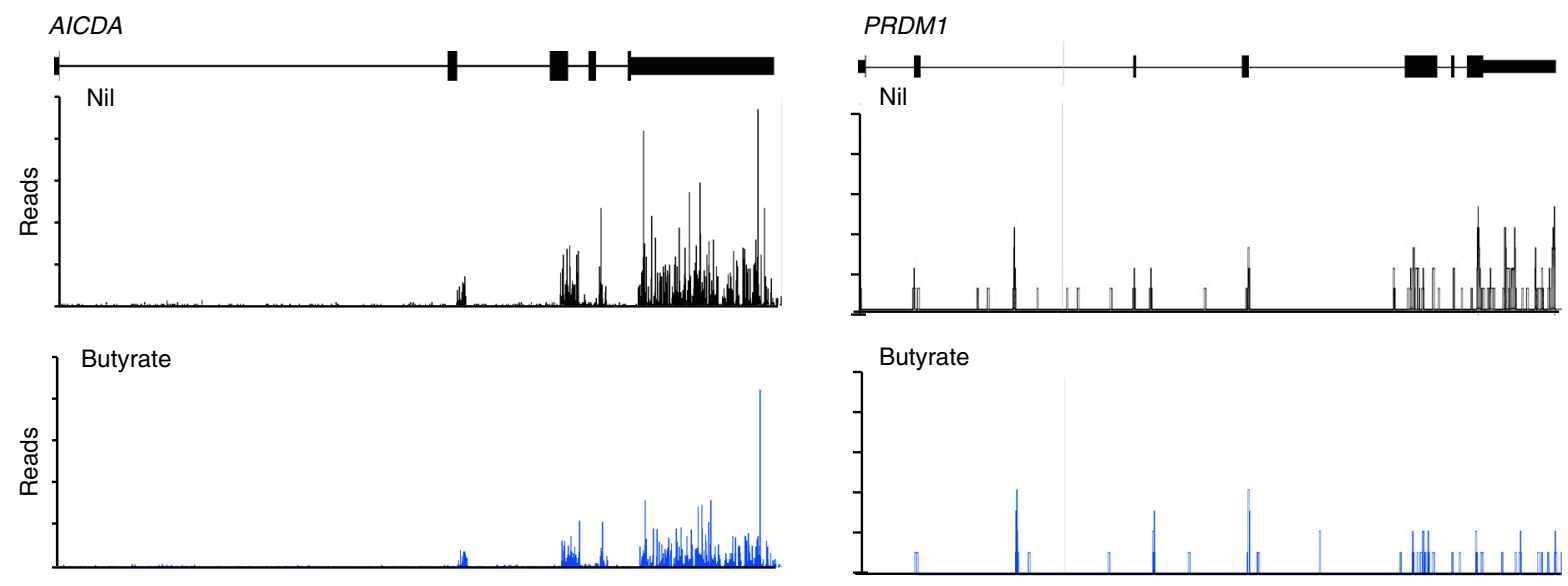

b

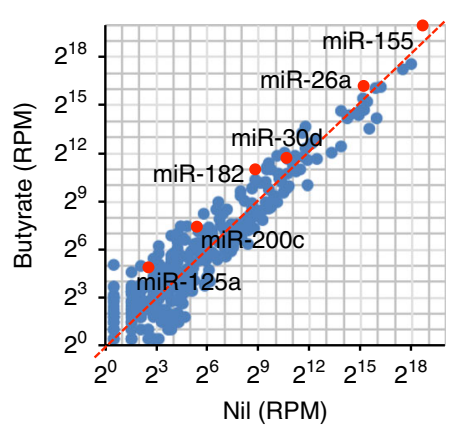

d

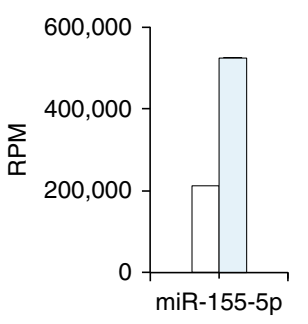

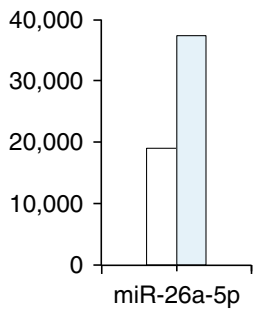

miRNAs targeting $A / C D A$
C

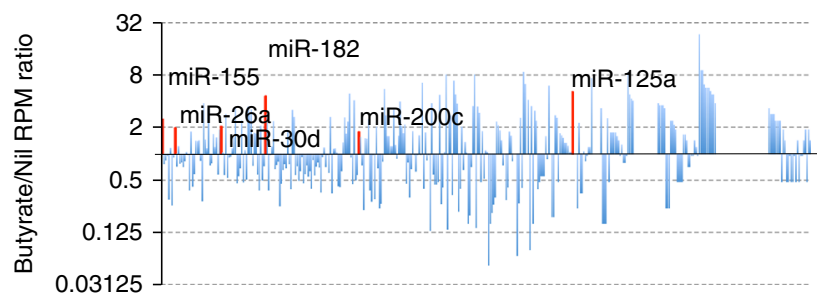

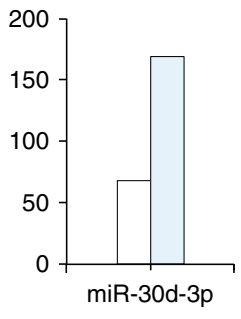

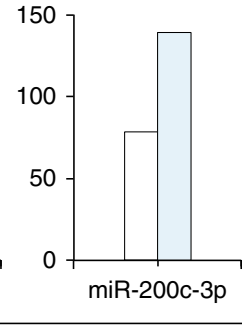

miRNAs targeting PRDM1

Fig. 9 Butyrate downregulates AICDA and PRDM1 expression while upregulating AICDA- and PRDM1-targeting miRNAs in human B cells. Purified human B cells were stimulated with CD154 plus IL-4 and IL-21 in the presence of nil or butyrate $(500 \mu \mathrm{M})$ for $60 \mathrm{~h}$ before preparation of RNA for mRNASeq and miRNA-Seq. a Profile of RNA-Seq reads at the AICDA and PRDM1 loci. b Scatter plots of miRNA expression as defined by miRNA-Seq (RPKs) in B cells treated with butyrate versus that in B cells treated with nil. $\mathbf{c}$ Bar graphs depict the fold changes in the average miRNA expression (RPMs) comparing $B$ cells treated with nil or butyrate. d B-cell expression of AICDA- or PRDM1-targeting miRNAs, as analyzed by miRNA-Seq.

in both human and mouse B cells, and directly modulate B-cell differentiation by acting as HDAC inhibitors, not as energy source or, for that matter, GPR signaling. This is further supported by the previous finding by us and others that, like butyrate and propionate, VPA, SAHA, TSA, and panobinostat (potent pharmacologic HDAC inhibitors that do not function as energy substrates or trigger GPR signaling in B cells) effectively dampened antibody or autoantibody responses $8,33,34,49$.

At low doses, butyrate and propionate increased expression of AID, germline $\mathrm{I}_{\mathrm{H}^{-}} \mathrm{C}_{\mathrm{H}}$ transcripts and CSR in vitro, albeit at a low degree, a reflection of increased histone acetylation of Aicda regulatory regions and $I g H$ locus, as mediated by SCFAs HDAC inhibitory activity. In mice immunized with NP-LPS, comparable low doses of SCFAs increased, at a low degree, AID and Blimp1 expression as well as the NP-binding IgG3 and IgG2b response. Our interpretation of these findings in vitro an in vivo is that while SCFA-induced Aicda- and Prdm1-targeting miRNAs inhibited Aicda and Prdm1 in a dose-dependent fashion over a wide physiological (SCFAs) range, the Aicda- and Prdm1-targeting miRNAs-mediated inhibition of Aicda and Prdm1 expression by low SCFAs doses was not robust enough to override the enhancement of CSR caused by the increased Aicda histone acetylation and germline $\mathrm{I}_{\mathrm{H}}-\mathrm{C}_{\mathrm{H}}$ transcription (Supplementary Fig. 14). This would also provide a mechanistic explanation for the moderate enhancement of classswitched antibodies reported by Kim et al. ${ }^{12}$.

Inhibition of Aicda and Prdm1 expression by SCFAs was mediated by enhanced histone acetylation of host genes of select miRNAs targeting Aicda and Prdm1 mRNAs. Like pharmacological HDI VPA ${ }^{8,33}$, butyrate enhanced the expression of miR-26a, miR-155, and miR-181b which target Aicda, and miR-30c, miR182, miR-200c and let-7a which target Prdm1, as well as miR125a which target both Aicda and Prdm1 mRNAs, thereby implying a selectivity of these SCFAs for different HDACs ${ }^{50}$. Butyrate and, likely, propionate target and inhibit HDAC1, HDAC2, and HDAC3, and, to a lesser extent, other members of 
a
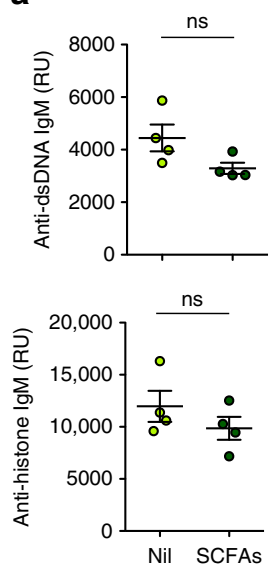

b
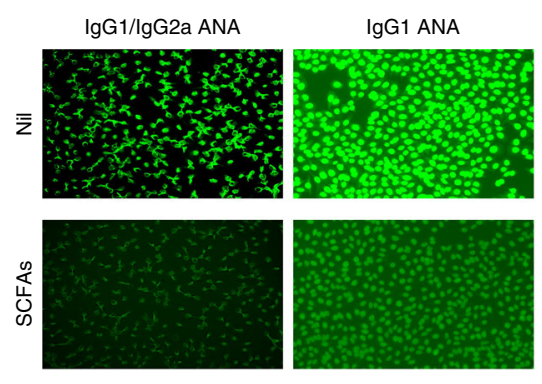

e

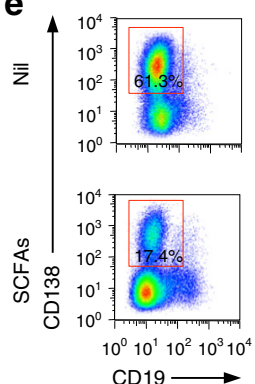

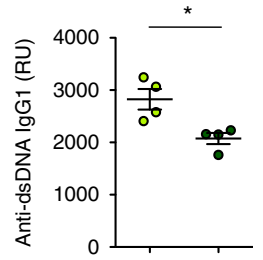

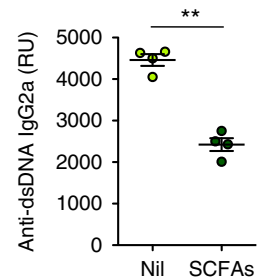

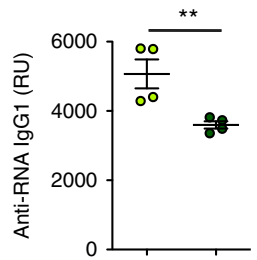

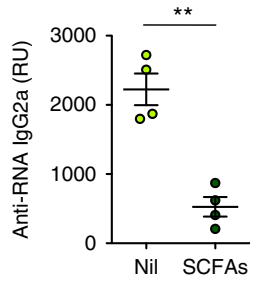

C
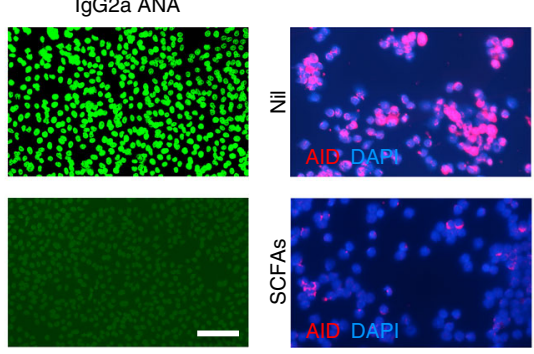

f

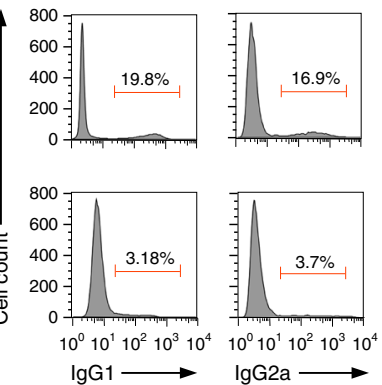

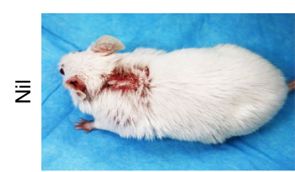

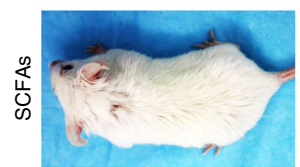

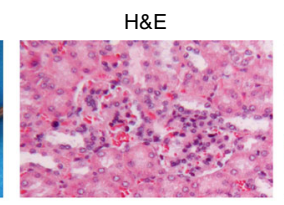

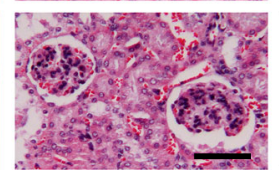

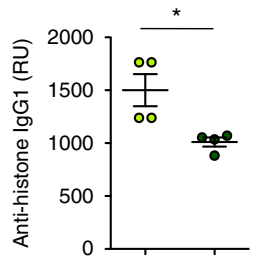

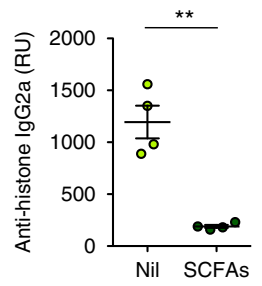

d - Isotype control
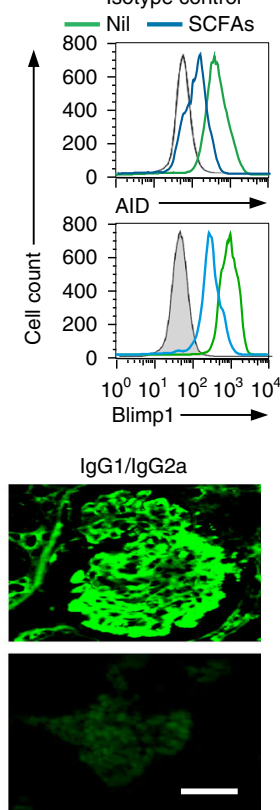

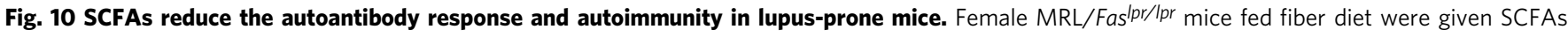
water (SCFAs) or plain water (Nil) starting at the age of 5 weeks and killed at 17 weeks of age. a Titers of circulating anti-dsDNA IgM, and anti-dsDNA, anti-RNP/Sm, anti-histone, and anti-RNA IgG1 and IgG2a (relative units, RU), as analyzed by specific ELISAs. Each symbol represents an individual mouse ( $n=4$ per group, pooled from two experiments). The bars represent the mean \pm SD. $\mathbf{b}$ ANA visualized by indirect immunofluorescence on HEp- 2 cells that were incubated with sera (1:400 dilution) from the MRL/Fas Ip/lpr mice using FITC-labeled rat mAbs to mouse IgG1 and IgG2a. Data are from one of three independent experiments yielding comparable results. c, d AID and Blimp1 expression as analyzed by intracellular staining followed by fluorescence microscopy (c) and flow cytometry (d). e Spleen surface CD138 ${ }^{+}$plasmablasts/plasma cells, and intracellular $\mathrm{CD} 138^{+} \operatorname{lgG1}{ }^{+}$and $\mathrm{CD} 138^{+} \mathrm{IgG2a^{+ }}$ plasmablasts/plasma cells as analyzed by flow cytometry. Data are representative of three independent experiments yielding comparable results. $\mathbf{f}$ Dorsal skin lesions (left panels), kidney sections stained with H\&E (middle panels), and kidney sections stained with FITC-labeled rat mAbs to mouse IgG1 and $\operatorname{lgG} 2 \mathrm{a}$ (right panels). Data are representative of three independent experiments. ${ }^{\star} p<0.05,{ }^{\star \star} p<0.01,{ }^{\star \star \star} p<0.001$, ns: not significant (unpaired $t$ test). Scale bar $=50 \mu \mathrm{m}(\mathbf{b}), 20 \mu \mathrm{m}$ (c), and $100 \mu \mathrm{m}(\mathbf{f})$. The source data are provided in Source Data file.

class I and class IIa HDACs ${ }^{50,51}$. Like histone acetyltransferases (HATs), HDACs do not directly bind to DNA; rather, they primarily associate with multiprotein complexes, the role and composition of which are often cell-type specific ${ }^{52}$. HDACassociated proteins can further specify the selectivity of HDIs, which display different affinities for different HDAC/cofactor complexes $^{53}$, as occurring in B lymphocytes, particularly when in an activated state. We refer to these compounded and sequential specificities of HDAC inhibitors as "HDAC inhibitors' pathways of selectivity". Finally, in addition to enhancing acetylation of histones, HDIs would increase acetylation of Drosha, an RNase III enzyme critical for miRNA biogenesis, and prevent its degradation by ubiquitination ${ }^{54}$. Thus, SCFAs not only enhance expression of host genes of select miRNAs targeting the Aicdal AICDA and Prdm1/PRDM1 mRNA-3'UTRs but may also promote biogenesis of such miRNAs by increasing Drosha stability.

SCFAs-mediated modulation of antibody and autoantibody responses would be altered by changes of the gut microbiota. In human, the gut Firmicutes/Bacteroidetes ratio has been positively correlated with SCFAs concentration ${ }^{55}$. Accordingly, a higher Firmicutes/Bacteroidetes ratio in our mice fed a fiber diet was associated with a reduced class-switched antibody response, as compared with the mouse counterparts fed a no-fiber diet. Along the same line, a higher Firmicutes/Bacteroidetes ratio and an 
increased concentrations of SCFAs occur in obese people ${ }^{56,57}$, who display a deficient antibody response ${ }^{58}$, further supporting a critical role of SCFAs in modulating B-cell CSR/SHM and plasma cell differentiation. In one case, a low Firmicutes/Bacteroidetes ratio was similarly associated with increased IgA levels, but in mice on a high fiber $\operatorname{diet}^{27}$. This is seemingly at odd with our findings showing a strict relationship between fiber diet or high SCFAs concentrations and decreased IgA as well as IgG and IgE, and might have been influenced by other parameters, including mouse vendor (Jackson Laboratory vs. Harlan Laboratories)dependent variations in gut microbiota and variations in husbandry facilities.

The gut microbiota elicits production of Ig of all isotypes, particularly IgA, as suggested by the greatly reduced IgA levels in germ-free animals ${ }^{59}$. Generally, most luminal IgAs are directed against intestinal flora ${ }^{60,61}$, possibly resulting from direct activation of B-cell BCR/TLRs by gut microbial commensals. Our demonstration of SCFA-mediated reduction of CSR to IgA in vitro as well as in vivo offers an explanation for the finding that administration of vancomycin, an antibiotic that clears a majority of SCFA-producing bacteria, leads to greatly increased serum IgA titers $^{60}$. These may also result from increased levels of gut acetate, which enhances expression and/or activity of retinal dehydrogenase. In DCs, this converts vitamin A into its metabolite retinoic acid (RA), a booster of CSR to $\operatorname{IgA}^{13,27}$.

Our findings unveiled a direct and B-cell-intrinsic mechanism by which dietary fiber-derived SCFAs modulate B-cell differentiation processes that critically underpin effective T-dependent and T-independent antibody responses, as well as autoantibody responses. SCFAs-mediated decrease in autoantibody levels and amelioration of the skin and kidney immunopathology in lupusprone MRL/Fas ${ }^{l p r / p r}$ and NZB/W F1 mice open a possibility for a new potential therapeutic use of SCFAs in systemic lupus erythematosus. Like for CSR to IgG and IgA, SCFAs also inhibited CSR to IgE by acting directly on B cells and dampened total and antigen (OVA)-specific IgE titers, suggesting that SCFAs may also reduce IgE-mediated allergic response. In a physiological state, SCFAs would play an important role in maintaining host-defense homeostasis that prevents dysregulated antibody responses that can lead to autoimmunity or allergy. Further, they would keep the overall reactivity to digestive and respiratory commensals in a dynamic equilibrium. Such an equilibrium may be altered upon alterations of the gut microbiota (e.g., by bacterial or viral infections), leading to reduced levels of SCFAs and enhancement of antibody and autoantibody responses. Thus, our findings outline an important B-cell-intrinsic mechanism that takes cues from environmental epigenetic modifiers, i.e., dietary fibers and related catabolites by intestinal microbiota, to regulate B-cell differentiation processes critical to antibody and autoantibody responses.

\section{Methods \\ Mice. C57BL/6, MRL/Fas ${ }^{l p r / p r}$ (MRL/MpJ-Fas ${ }^{l p r} / \mathrm{J}$, 000485), NZB/W F1 (NZB/ WF1/J, 100008), Tcr $\beta^{-/-T c r \delta^{-/-}}$(B6129P2-Tcr $\left.\beta^{\text {tm1Mom }} \operatorname{Tcr}^{\text {tm } 1 M o m} / \mathrm{J}, 002122\right)^{42}$, and NSG (NOD.Cg-Prkdcscid Il2rgtm1Wjl/SzJ, 005557) ${ }^{43}$ mice were purchased from the Jackson Laboratory (Bar Harbor, Maine), Aicda ${ }^{-1-}$ mice (C57BL/6 back- ground) were obtained from Dr. Tasuku Honjo (Kyoto University, Kyoto, Japan). The mice were housed and bred in our pathogen-free vivarium. All animal experiments were conducted in accordance with the guidelines and approved by the Institutional Animal Care and Use Committee (IACUC) of the University of Texas Health Science Center at San Antonio.}

Fiber diet, no-fiber diet, and SCFAs water. After weaning, mice were fed a regular chow diet, referred hereafter as "fiber diet" (Takland Mouse/Rat Sterilizable Diet LM-485-containing 18\% fibers) or a no-fiber diet (Harlan laboratories TD.00129 AIN-93G No Cellulose-containing 0\% fibers). Mice fed a fiber or nofiber diet were then given drinking water-containing SCFAs (SCFAs water, $\mathrm{pH}=$ 7.4 , containing $20.0 \mathrm{mg} \mathrm{ml}^{-1}$ tributyrin emulsion, $140 \mathrm{mM}$ sodium butyrate, and
$150 \mathrm{mM}$ sodium propionate), water containing a low dose of SCFAs ( $\mathrm{pH}=7.4,20$ $\mathrm{mM}$ sodium butyrate, and $30 \mathrm{mM}$ sodium butyrate) or plain water $(\mathrm{pH}=7.4$, sodium-adjusted to match SCFAs water) starting at the age of 5 weeks. Tributyrin is a triglyceride butyrate analog which has a long in vivo half-life and act as a prodrug of butyrate. It is cleaved by intracellular lipases and hydrolyzed into three molecules of butyrate ${ }^{62}$. In mice fed the fiber diet, administration of the SCFAs water resulted in $20-200 \mu \mathrm{M}$, or $18-20 \mu \mathrm{mol} \mathrm{g} \mathrm{g}^{-1}$ butyrate and propionate, in the circulation and feces, respectively. Drinking water-containing SCFAs at the above concentration was always well accepted by all mice used in this study.

SCFAs modulation of T-dependent and $\mathrm{T}$-independent antibody responses. To analyze local (intestinal) and systemic T-dependent antibody response to OVA, C57BL/6 mice fed a fiber or no-fiber diet, and SCFAs water or plain water ad libitum, were administered OVA (20 mg) plus mucosal adjuvant cholera toxin (List Biological Labs, $20 \mu \mathrm{g}$ ) in $500 \mu \mathrm{l}$ PBS via intragastric gavage once a week for 4 weeks, and killed 1 week after the last OVA and cholera toxin administration for all studies. For analysis of the T-dependent antibody response to NP, C7BL/6 mice

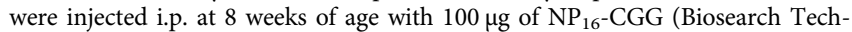
nologies) in $100 \mu \mathrm{l}$ of alum (Inject Alum, Pierce) and boost-injected with $100 \mu \mathrm{g}$ of $\mathrm{NP}_{16}$-CGG in PBS 3 weeks later. For analysis of the T-independent antibody response to NP, C7BL/6 or $T \mathrm{cr} \beta^{-/-} \mathrm{Tcr} \delta^{-/-}$mice were fed a fiber diet and SCFAs water or plain water ad libitum, and injected i.p. at 8 weeks of age with $50 \mu \mathrm{g}$ of NP-LPS (Biosearch Technologies) in $100 \mu \mathrm{l}$ of PBS, and boost-injected with $50 \mu \mathrm{g}$ of NP-LPS in $100 \mu \mathrm{l}$ of PBS 3 weeks later. All mice were killed 1 week after the boost injection.

NSG/B mice. NSG/B mice were generated by grafting NSG mice with highly purified C57BL/6 B cells. Such B cells were purified from splenocytes of 8-12 weeks old C57BL/6 mice by negative selection using the EasySep ${ }^{\text {sm }}$ Mouse B Cell Isolation Kit (STEMCELL Technologies) following the manufacturer's instructions. Purified $B$ cells were injected intravenously $\left(20.0 \times 10^{6}\right.$ cells per mouse in $250 \mu \mathrm{l}$ PBS in lateral tail veins) into 8-week-old NSG mice. After B-cell engraftment, mice were stated on SCFAs water or plain water (until the end of the experiment) and i.p. injected with NP-LPS (50 $\mu \mathrm{g}$ in PBS) at days $0,2,4$, and 6 , and killed 1 week after the last NP-LPS injection.

Detection of antibodies and autoantibodies. Titers of IgM, IgD, IgG, IgG1, IgE and IgA from in vitro culture supernatants of stimulated human and mouse B cells or titers of circulating or fecal total and/or NP-binding IgM, IgG1, IgA, IgG2b, and IgG3 were measured using specific ELISAs, as we described ${ }^{33,63-65}$. OVAbinding IgE were detected by sandwich ELISAs, using plates coated with rat antimouse IgE mAb (23G3, Southern Biotech) (Supplementary Table 1). Serial twofold diluted serum samples in PBS- $(0.05 \%)$ Tween 20 (PBS-Tween 20 ) were added to the plates and incubated for $2 \mathrm{~h}$ at $23^{\circ} \mathrm{C}$. After washing with PBS-Tween 20, biotinOVA (152060, GALAB) was added. After a final washing, IgE-bound antigens were detected using streptavidin-horseradish peroxidase.

Anti-dsDNA, anti-RNP/Sm, anti-histone, and anti-RNA IgM, IgG1, and IgG2a autoantibody titers in sera of MRL/Fas ${ }^{l p r / l p r}$ and NZB/W F1 mice were measured by specific ELISAs, as described ${ }^{33,66}$, except that for anti-RNP/Sm, anti-histone, and anti-RNA Abs, plates were coated with RNP/Sm (MBS318132, MyBioSource), histone (H9250, Sigma-Aldrich) or mouse liver total RNA, respectively. Antigenspecific antibody titers are expressed as relative units (RU), defined as the dilution factor needed to reach 50\% saturation binding, as calculated using GraphPad Prism ${ }^{\circledast}$ software (GraphPad). To detect antinuclear antibody (ANA), sera were serially diluted in PBS (from 1:50 to 1:400), incubated on antinuclear Ab substrate slides (HEp-2 cell-coated slides, MBL-BION), and detected with FITC-anti-IgG1 (A85-1, BD Biosciences), FITC-anti-IgG2a mAb (R19-15, BD Biosciences), or 1:1 mixture of FITC-anti-IgG1 and FITC-anti-IgG2a mAbs. Images were acquired with $\mathrm{a} \times 20$ objective on a fluorescence microscope.

To analyze kidney IgG deposition, kidneys from MRL/Fas ${ }^{l p r / l p r}$ and NZB/W F1 mice were fixed in paraformaldehyde (PFA, 4\%) and paraffin embedded for immunofluorescence imaging. For immunofluorescence, $5 \mu \mathrm{m}$ sections were prepared by cryostat, loaded onto positively charged slides, fixed in cold acetone, and stained with a mixture of anti- to mouse IgG1 FITC-labeled rat mAb and antito mouse IgG2a FITC-labeled rat mAb. Cover slips were mounted using ProLong Gold Antifade Reagent, before examination under the fluorescence microscope.

Detection of bacteria-binding and bacteria-bound antibodies. Serum bacteriabinding IgM and IgA were analyzed by ELISA using plates coated with bacteria. Freshly cultured E. coli were washed with PBS, heat inactivated at $65^{\circ} \mathrm{C}$ for $15 \mathrm{~min}$, and resuspended in water $\left(200 \mu \mathrm{g} \mathrm{ml}^{-1}\right)$. In total, $50 \mu \mathrm{l}$ of bacteria suspension was added to each well of a 96-well ELISA plate and dried overnight in a $37^{\circ} \mathrm{C}$ incubator. Plates were washed three times with PBS-Tween 20 and blocked with $1 \%$ (v/ w) BSA in PBS for $1 \mathrm{~h}$ at room temperature. Mouse sera were serially twofold diluted from 1:20 and incubated for $2 \mathrm{~h}$ at $37^{\circ} \mathrm{C}$. Bacteria-binding IgM and IgA were then detected using anti-mouse IgM or anti-mouse IgA mAb.

To detect bacteria-bound $\operatorname{IgM}, \operatorname{IgD}, \operatorname{IgG} 1$, and $\operatorname{IgA}$, feces $(10 \mathrm{mg})$ were suspended in $100 \mu \mathrm{l}$ 1x PBS (filtered through $0.2-\mu \mathrm{m}$ filter), homogenized and centrifuged at $400 \times \mathrm{g}$ for $5 \mathrm{~min}$ to remove large particles. The supernatant was then 
centrifuged at $8000 \times g$ for $10 \mathrm{~min}$ to remove non-bound antibodies (in supernatant). The bacterial pellet was suspended in $1 \mathrm{ml}$ of PBS with $1 \%(\mathrm{w} / \mathrm{v})$ BSA. After fixation with $7.2 \%$ formaldehyde for $10 \mathrm{~min}$ at room temperature, bacteria were washed with PBS, and stained with PE-anti-IgM mAb (AF6-78, BD Biosciences), FITC-anti-IgG1 mAb (406606, BD Biosciences) or FITC-anti-IgA $\mathrm{mAb}$ (C10-3, BD Biosciences) on ice for $30 \mathrm{~min}$, washed with PBS, and further resuspended in $1 \times$ PBS containing $0.2 \mu \mathrm{g} \mathrm{m}^{-1}$ DAPI for flow cytometry analysis. All events that stained with DAPI were considered as bacteria.

SCFAs concentrations and HDAC activity. Concentrations of SCFAs in the spleen, colon tissues, and MLNs were analyzed by a Gas chromatography-mass spectrometry (GC-MS) method (Creative Proteomics). The tissues were homogenized in $1.0 \mathrm{ml}$ of ethanol (containing $0.5 \% \mathrm{HCl}, \mathrm{V} / \mathrm{V}$ ) by ultrasonication. The homogenates were centrifuged at $12,000 \mathrm{~g}$ for $10 \mathrm{~min}$. The supernatants were analyzed using a GC-MS Agilent 7890-5977 system. $\mu \mathrm{M}$ concentrations of tissue SCFAs were derived from $\mu \mathrm{mol} \mathrm{g}^{-1}$ tissue concentrations using the formula: $\mu \mathrm{M}$ $(\mu \mathrm{mol}$ per $\mathrm{l})=\mu \mathrm{mol} \mathrm{Kg}{ }^{-1}$ divided by tissue density $\left(\mathrm{g} \mathrm{ml}^{-1}\right)$. Fecal and serum SCFA concentrations were analyzed by the UT Health Long School of Medicine Mass Spectrometry Laboratory using a LC-MS/MS system (Q Exactive ${ }^{\mathrm{Tn}} \mathrm{Hybrid}$ Quadrupole-Orbitrap Mass Spectrometer, Thermo Fisher). Feces (100 mg) were first homogenized in $400 \mu \mathrm{l}$ of deionized water by crushing and vortex them vigorously until all solid content passed into solution. Acidify sera and fecal samples were added with $25 \%$ metaphosphoric acid at 1:5 ratio (one volume of acid for five volumes of sample) for 30 mins on ice. Samples were then centrifuged at 12,000 g for $15 \mathrm{~min}$ at $4{ }^{\circ} \mathrm{C}$, and supernatants were filtered using Ultrafree MC columns (Millipore). The HDAC inhibitory activity of SCAFs was analyzed in B cells stimulated with LPS plus IL-4 in the presence of nil or different concentrations of sodium acetate, sodium butyrate, or sodium propionate for 48 or $72 \mathrm{~h}$. In such B cells, the HDAC activity was measured using a HDAC Cell-Based Activity Assay kit (600150, Cayman).

Microbiota analysis. Microbial DNA was extracted from mouse feces using Quick-DNA $^{\mathrm{m}}$ Fecal/Soil Microbe Microprep Kit (Zymo Research) according to the manufacturer's instructions. To determine the composition of the bacterial phyla present in feces of the mice fed different diets, isolated bacterial DNA was tagged and sequenced using miSeq platform. The V3-V4 hypervariable region of the bacteria $16 \mathrm{~S}$ rRNA gene was amplified by PCR using tagged bact-341F primer $5^{\prime}$-T CGTCGGCAGCGTCAGATGTGTATAAGAGACAGCCTACGGGNGGC WGC AG-3' and bact-805R primer 5'-GTCTCGTGGGCTCGGAGATGTGTATAAGAG ACAGGACTACHVGGGTATCTAATCC- $3^{\prime}$ and Phusion DNA polymerase. Multiplexing indices and Illumina sequencing adapters were then added to the amplicons by limited-cycle amplification using the Nextera XT Index Kit (Illumina). The libraries were normalized and pooled, and sequenced on the MiSeq system (Illumina). Sequencing and quality assessment were performed at UT Health Genome Sequencing Facility. Bacterial taxonomy was assigned using the Ribosomal Database Project (RDP) classifier ${ }^{67}$

Detection of antibody-forming cells (AFCs). Spleen, bone marrow, MLN, and PP cells were isolated from desired mice and analyzed for AFCs by ELISPOT. MultiScreen ${ }^{\oplus}$ ELISPOT plates (MAIPS4510, Millipore) were activated with ethanol (35\%), washed four times with PBS and coated with unlabeled rabbit polyclonal antibodies against mouse $\operatorname{IgM}, \operatorname{IgG} 1$, or IgA in PBS overnight at $4{ }^{\circ} \mathrm{C}$. The plates were then washed six times with PBS, blocked with BSA $(0.5 \%)$ in RPMI/HEPES plus L-glutamine for $1 \mathrm{~h}$ at room temperature. Single-cell suspensions from lamina propria, bone marrow, and spleen cells of OVA-immunized mice were cultured in the plates at $37^{\circ} \mathrm{C}$ for $16 \mathrm{~h}$ in FCS-RPMI at 250,000, 125,000, and 75,000 cells per well. The cultures were then removed, the plates were washed six times, incubated with biotin-anti-IgM, IgG1, or IgA for $2 \mathrm{~h}$ on a shaker at room temperature, washed, incubated with horseradish peroxidase (HRP)-streptavidin (Santa Cruz Biotech) for $1 \mathrm{~h}$ on a shaker at room temperature, washed again and developed using the Vectastain AEC peroxidase substrate kit following the manufacturer's protocol (SK-4200, Vector Laboratories). Plates were imaged and quantified using a CTL-ImmunoSpot ${ }^{\oplus}$ Analyzer and software.

Flow cytometry. For surface staining, mononuclear cells were reacted with VFanti-CD19 mAb (75-0193-0100, Tonbo), PE-anti-IgM mAb (406507, BioLegend), APC-anti-IgG1 mAb (406609, BioLegend), FITC-anti-IgA mAb (C10-3, BD Biosciences), 7-AAD, PE-Cy7-anti-CD138 mAb (142513, BioLegend), APC-antiCD3 mAb (100221, BioLegend), APC-anti-CD4 (GK1.5, BioLegend), and/or APCanti-CD8 mAb (53-6.7, BD Biosciences). For intracellular staining, cells were stained with anti-CD19 mAb (Clone 1D3; Tonbo) and fixable viability dye eFluor 450 (FVD 450, eBiosciences) followed by incubation with the BD Cytofix/Cytoperm buffer at $4{ }^{\circ} \mathrm{C}$ for $20 \mathrm{~min}$. After washing twice with the BD Perm/Wash buffer, cells were resuspended in HBSS with $1 \%$ BSA and stored overnight at $4{ }^{\circ} \mathrm{C}$. Cells were then stained with FITC-anti-AID Ab (bs-7855R-FITC, Bioss), APCanti-Blimp1 mAb (5E7, BioLegend), PE-Cy7-anti-CD138 mAb, APC-anti-IgG1 mAb (406610, BioLegend), FITC-anti-IgG2a mAbs (553390, BD Biosciences), and/ or PE-anti-IgE mAb (23G3, eBioscience). FACS analysis was performed on singlecell suspensions. In all flow cytometry experiments, cells were appropriately gated on forward and side scattering to exclude dead cells and debris. Cell analyses were performed using a LSR-II flow cytometer (BD Biosciences), and data were analyzed using FlowJo software (TreeStar). All experiments were performed in triplicates.

Fluorescence microscopy. Fluorescence microscopy of tissues. To analyze IgM, IgD, and IgA-producing cells in the lamina propria and PPs, the intestine was folded into a "Swiss-roll", fixed with PFA (4\%), and embedded in paraffin. Ten micrometer sections were cut and heated at $80{ }^{\circ} \mathrm{C}$ to adhere to the slide, washed four times in xylene for $2 \mathrm{~min}$, dehydrated two times with $100 \%$ ethanol for $1 \mathrm{~min}$ two times with $95 \%$ ethanol for $1 \mathrm{~min}$, and washed two times in water for $1 \mathrm{~min}$. Antigens were unmasked using $2 \mathrm{mM}$ EDTA in $100^{\circ} \mathrm{C}$ for 40 mins followed by a cooling step at $25^{\circ} \mathrm{C}$ on the bench top, three times washing with $1 \mathrm{x}$ TBS and blocking using $10 \%$ BSA for $15 \mathrm{~min}$. Slides were again washed three times with $1 \mathrm{x}$ TBS and stained with PE-anti-IgM, primary-rabbit anti-mouse-IgA mAb (PA-130826, Thermo Fisher) followed by Alexa Fluor $488^{\circledast}$-anti rabbit-IgG $(\mathrm{H}+\mathrm{L}) \mathrm{F}$ $(\mathrm{ab})_{2} \mathrm{mAb}$ (4412, Cell Signaling), and FITC-anti-IgD mAb (405713, BioLegend), $\mathrm{PE}$ goat-anti-mouse-IgM mAb (406507, BioLegend) for $2 \mathrm{~h}$ in a moist dark chamber. After washing three times with Triton X-100 (0.1\%) in TBS, slides were air dried, and cover slips were mounted with ProLong ${ }^{\oplus}$ Gold Antifade Reagent with DAPI (Invitrogen). Fluorescence images were captured using a 10x objective lens with a Zeiss Axio Imager Z1 fluorescence microscope. To analyze the germinal center structure in spleen or IgD-producing cells in MLNs, $10 \mu \mathrm{m}$ spleen or MLN sections were prepared by cryostat and loaded onto positively charged slides, fixed in cold acetone and stained with PE-anti-GL-7 (144607, BioLegend) and FITC-anti-B220 mAbs (103206, BioLegend), or FITC-anti-IgD mAb (405704, BioLegend), respectively, for $1 \mathrm{~h}$ at $25^{\circ} \mathrm{C}$ in a moist chamber. Cover slips were then mounted using ProLong ${ }^{\circledR}$ Gold Antifade Reagent, before examination with a fluorescence microscope.

Fluorescence microscopy of B cells. B cells were suspended at $0.1 \times 10^{6}$ cells per100 $\mu \mathrm{l}$ in FCS-RPMI. Pre-labeled slides were then placed into cytofunnels and ran with $50 \mu$ of FCS-RPMI, in order to wet the cytofunnel paper. Cells were then placed again into the cytofunnel and spun at 800 RPM for 3 mins using Cytospin ${ }^{\text {tm }}$ 4 Cytocentrifuge (Thermo Fisher). For intracellular visualization of AID and Blimp1 proteins, the cells were fixed with methanol for $15 \mathrm{~min}$ and washed three times in PBS-Tween 20. Cells were then blocked in 10\% BSA for $15 \mathrm{~min}$ and stained with 1:20 Alexa 647-AID (bs-7855R-A647, Bioss), or Alexa 647-Blimp1 (150003, BioLegend) overnight in a dark moist chamber.

Human and mouse B cells, CSR, and plasma cell differentiation. Mouse $\operatorname{IgD}^{+}$ naïve $B$ cells were isolated from 8 - to 12 weeks-old C57BL/6 mice as described $^{33,64,65}$. B cells were resuspended in FCS-RPMI containing $50 \mathrm{mM} \beta$ mercaptoethanol and $1 \mathrm{x}$ antibiotic-anti-mycotic mixture (15240-062, Invitrogen) at $37^{\circ} \mathrm{C}$ in 48 -well plates and stimulated with LPS $\left(3 \mu \mathrm{g} \mathrm{ml}{ }^{-1}\right)$ or CD154 (1 $\mathrm{U} \mathrm{ml}^{-1}$, obtained from membrane fragments of CD154 encoding recombinant baculovirus-infected Sf21 insect cells) plus IL-4 ( $5 \mathrm{ng} \mathrm{ml}^{-1}$, R\&D Systems) for CSR to IgG1, IgE and plasma cell differentiation, LPS $\left(3 \mu \mathrm{g} \mathrm{ml}^{-1}\right)$ or CD154 $\left(1 \mathrm{U} \mathrm{ml}^{-1}\right)$ plus TGF- $\beta$ ( $2 \mathrm{ng} \mathrm{ml}^{-1}$, R\&D Systems), IL-4 (5 $\left.\mathrm{ng} \mathrm{ml}^{-1}\right)$, IL-5 (3 $\mathrm{ng} \mathrm{ml}^{-1}, \mathrm{R} \& \mathrm{D}$ Systems), anti- $\delta$ mAb-dextran (Fina Biosolutions) and RA (10 nM) for CSR to IgA, or LPS $\left(3 \mu \mathrm{g} \mathrm{ml}^{-1}\right)$ plus TGF- $\beta\left(2 \mathrm{ng} \mathrm{ml}^{-1}\right), \mathrm{IL}-4\left(5 \mathrm{ng} \mathrm{ml}^{-1}\right), \mathrm{IL}-5\left(3 \mathrm{ng} \mathrm{ml}^{-1}\right)$ and RA $(10 \mathrm{nM})$ for CSR to IgD. Butyrate $(50-500 \mu \mathrm{M})$, propionate $(25-2000 \mu \mathrm{M})$, palmitate $(64-125 \mu \mathrm{M}),(\mathrm{R})-(+)$-etomoxir $(25 \mu \mathrm{M})$, SAHA $(0.2$ or $0.3 \mu \mathrm{M})$, TSA $(0.001-1.6 \mu \mathrm{M})$, or GLPG0974 $(0.1-5.0 \mu \mathrm{M})$ were added to cultures, and cells were collected at various times.

Human $\mathrm{IgD}^{+}$naïve B cells ( $\sim 99 \%$ pure) were purified by negative selection from healthy donor PBMCs using the EasySep Human Naive B Cell Enrichment Kit (19254, STEMCELL Technologies), following the manufacturer's instructions. Naive B cells were then cultured in FCS-RPMI and stimulated with CD154 (10 U $\left.\mathrm{ml}^{-1}\right)$, IL-4 (20 $\mathrm{ng} \mathrm{ml}^{-1}, \mathrm{R} \& \mathrm{D}$ Systems), and IL-21 (50 $\mathrm{ng} \mathrm{ml}^{-1}, \mathrm{R} \& \mathrm{D}$ Systems) or CD154 $\left(10 \mathrm{U} \mathrm{ml}^{-1}\right), \mathrm{IL}-21\left(50 \mathrm{ng} \mathrm{ml}^{-1}\right)$, and TGF- $\beta\left(0.5 \mathrm{ng} \mathrm{ml}^{-1}\right)$ in the presence of nil, butyrate, propionate, or butyrate plus propionate for $120 \mathrm{~h}$. B cells were then stained with 7-aminoactinomycin D (7-AAD), FITC-anti-IgM mAb (314506, BioLegend), PE-anti-CD19 mAb (302208, BioLegend), and allophycocyanin-antiIgG mAb (562025, BD Biosciences) or 7-AAD, FITC-anti-IgA mAb (F5259, Sigma-Aldrich), and biotin-F( $\left(\mathrm{ab}^{\prime}\right)_{2}$ anti-IgM (2022-08, Southern Biotech), followed by allophycocyanin-streptavidin, and analyzed by flow cytometry.

Immunoblotting. B cells from C57BL/6 mice were stimulated with LPS ( $\left.3 \mu \mathrm{g} \mathrm{ml}^{-1}\right)$ plus IL-4 $\left(4 \mathrm{ng} \mathrm{ml}^{-1}\right)$ in the presence of nil, butyrate $(500 \mu \mathrm{M})$, propionate $(2000$ $\mu \mathrm{M})$, or butyrate $(500 \mu \mathrm{M})$ plus propionate $(2000 \mu \mathrm{M})$ for $72 \mathrm{~h}$. Cells were harvested and lysed in Laemmli buffer. Cell extracts containing equal amounts of protein $(20 \mu \mathrm{g})$ were fractionated through SDS-PAGE (10\%). The fractionated proteins were transferred onto polyvinylidene difluoride membranes (Bio-Rad Laboratories) overnight $(30 \mathrm{~V})$ at $4{ }^{\circ} \mathrm{C}$. After blocking and overnight incubation at $4^{\circ} \mathrm{C}$ with anti-AID (ZA001, Invitrogen), anti-Blimp1 (6D3, eBioscience), antiacetyl-histone H3 (H3K9ac/K14ac, 17-615, Millipore), anti-histone H3 (601901, BioLegend), or anti- $\beta$-Actin mAb (AC-15, Sigma-Aldrich), the membranes were incubated with HRP-conjugated secondary Abs. After washing with PBS-Tween 20, bound HRP-conjugated Abs were detected using Western Lightning Plus- 
Enhanced Chemiluminescence reagents (PerkinElmer Life and Analytical Sciences).

Quantitative RT-PCR of mRNA, miRNA, germline, post-recombination, and mature transcripts. For quantification of mRNA, pri-miRNA, germline $\mathrm{I}_{\mathrm{H}} \mathrm{C}_{\mathrm{H}}$, post-recombination $\mathrm{I} \mu-\mathrm{C}_{\mathrm{H}}$, and mature $\mathrm{V}_{\mathrm{H}} \mathrm{DJ}_{\mathrm{H}^{-}} \mathrm{C}_{\mathrm{H}}$ transcripts, RNA was extracted from $0.2-5.0 \times 10^{6}$ cells using either Trizol ${ }^{\oplus}$ Reagent (Invitrogen) or RNeasy Plus Mini Kit (Qiagen). Residual DNA was removed from the extracted RNA with gDNA eliminator columns (Qiagen). cDNA was synthesized from the total RNA with the SuperScript ${ }^{\mathrm{TM}}$ III First-Strand Synthesis System (Invitrogen) using oligo-dT primer. Transcript expression was measured by qRT-PCR with the appropriate primers (Supplementary Table 2) using a Bio-Rad MyiQ ${ }^{\mathrm{TM}}$ Real-Time PCR Detection System (Bio-Rad Laboratories) to measure SYBR Green (IQ ${ }^{\mathrm{TM}}$ SYBR $^{\oplus}$ Green Supermix, Bio-Rad Laboratories) incorporation with the following protocol: $95^{\circ} \mathrm{C}$ for $15 \mathrm{~s}, 40$ cycles of $94^{\circ} \mathrm{C}$ for $10 \mathrm{~s}, 60^{\circ} \mathrm{C}$ for $30 \mathrm{~s}$, $72^{\circ} \mathrm{C}$ for $30 \mathrm{~s}$. Data acquisition was performed during $72^{\circ} \mathrm{C}$ extension step. Melting curve analysis was performed from 72 to $95^{\circ} \mathrm{C}$. For quantification of mature miRNA transcripts, RNA was extracted from $0.2-5.0 \times 10^{6}$ cells using miRNeasy ${ }^{\circ}$ Mini Kit (Qiagen) and then reverse-transcribed with miScript II RT Kit (Qiagen) using the miScript HiSpec buffer. A Bio-Rad MyiQ ${ }^{\mathrm{TM}}$ Real-Time PCR Detection System was used to measure SYBR Green (miScript SYBR Green PCR Kit, Qiagen) incorporation according to the manufacturer's instructions. Mature miRNA forward primers (Supplementary Table 1) were used at $250 \mathrm{nM}$ in conjunction with the Qiagen miScript Universal Primer and normalized to expression of small nuclear/nucleolar RNAs Rnu6/RNU61/2, Snord61/ SNORD61, Snord68/SNORD68, and Snord70/SNORD70. The $\Delta \Delta$ Ct method was used for data analysis of qRT-PCR experiments.

SHM analysis. To analyze Ig SHM induced in response to NP immunization, spleen $\mathrm{B}$ cells were isolated from $\mathrm{NP}_{16}$-CGG-injected C57BL/6 mice, NP-LPSinjected C57BL/6, $T c r \beta^{-/-} \mathrm{Tcr}^{-/-}$, and NSG/B mice for RNA extraction using the RNeasy Mini Kit (Qiagen). cDNA was synthesized from 1 to $2 \mu \mathrm{g}$ of the total RNA with the SuperScript ${ }^{\mathrm{m}}$ III First-Strand Synthesis System (Invitrogen) using the oligo-dT primer. Rearranged $\mathrm{V}_{186.2} \mathrm{DJ}_{\mathrm{H}^{-}} \mathrm{C} \gamma 1, \mathrm{~V}_{186.2} \mathrm{DJ}_{\mathrm{H}}-\mathrm{C} \gamma 2 \mathrm{~b}$, or $\mathrm{V}_{186.2} \mathrm{DJ}_{\mathrm{H}^{-}} \mathrm{C} \gamma 3$ cDNA encoding the anti-NP IgH chain was amplified using a $V_{186.2}$ leader-specific forward primer together with a reverse $\mathrm{C} \gamma 1-, \mathrm{C} \gamma 2 \mathrm{~b}-$, or $\mathrm{C} \gamma 3$-specific primer $^{33}$ tagged with Illumina clustering adapters and Phusion ${ }^{\mathrm{mt}}$ high-fidelity DNA polymerase (New England BioLabs). Amplification conditions were $98^{\circ} \mathrm{C}$ for $10 \mathrm{~s}, 60^{\circ} \mathrm{C}$ for $45 \mathrm{~s}$, and $72{ }^{\circ} \mathrm{C}$ for $1 \mathrm{~min}$ for 30 cycles. The amplified library was tagged with barcodes for sample multiplexing, PCR enriched, and annealed to the required Illumina clustering adapters. High-throughput $300 \mathrm{bp}$ pair-ended sequencing was performed using the Illumina MiSeq system. Somatic mutations in $\mathrm{V}_{186.2}$ (IMGT V1-72) segments were analyzed using IMGT/HighV-QUEST (The international ImMunoGeneTics information system ${ }^{\oplus}$, http://www.imgt.org).

Analysis of histone acetylation by ChIP-qPCR. ChIP assays were performed as described ${ }^{6,33,64,65}$. B cells $\left(1 \times 10^{7}\right)$ were treated with formaldehyde $(1 \% \mathrm{v} / \mathrm{v})$ for 10 min at $25^{\circ} \mathrm{C}$ to cross-link chromatin, washed once in cold PBS with protease inhibitors (Roche), and resuspended in lysis buffer (20 mM Tris-HCl, $200 \mathrm{mM}$ $\mathrm{NaCl}, 2 \mathrm{mM}$ EDTA, $0.1 \% \mathrm{w} / \mathrm{v}$ SDS, and protease inhibitors, $\mathrm{pH}$ 8.0). Chromatin was sonicated to yield DNA fragments (about 200 to $1000 \mathrm{bp}$ in length), precleared with protein A agarose beads (Pierce) and incubated with anti-acetylhistone $\mathrm{H} 3 \mathrm{mAb}$ (H3K9ac/K14ac, 17-615, Millipore) at $4{ }^{\circ} \mathrm{C}$ overnight. Immune complexes were precipitated by Protein A agarose beads, washed and eluted (50 $\mathrm{mM}$ Tris- $\mathrm{HCl}, 0.5 \%$ SDS, $200 \mathrm{mM} \mathrm{NaCl}, 100 \mu \mathrm{g} \mathrm{ml}^{-1}$ proteinase $\mathrm{K}, \mathrm{pH} 8.0$ ), followed by incubation at $65^{\circ} \mathrm{C}$ for $4 \mathrm{~h}$. DNA was purified using a QIAquick PCR purification kit (Qiagen). The miRNA host gene, Aicda, Prdm1 and $\mathrm{I}_{\mathrm{H}}$ promoter region DNAs were amplified from immunoprecipitated chromatin by qPCR using appropriate primers (Supplementary Table 1). Data were normalized to input chromatin DNA and depicted as relative abundance of each amplicon.

High-throughput mRNA-Seq and miRNA-Seq. The total RNA was extracted from $2 \times 10^{6}$ cells using miRNeasy ${ }^{\circ}$ Mini Kit (Qiagen), as described ${ }^{33}$. RNA integrity was verified using an Agilent Bioanalyzer 2100 (Agilent). Next-generation mRNA-Seq and small RNA-Seq were performed by the UT Health Genome Sequencing Facility ${ }^{8}$. High-quality RNA (RNA integrity number or RIN.9.0) was processed using an Illumina TruSeq RNA sample prep kit v2 or TruSeq Small RNA Sample Prep kit following the manufacturer's instructions (Illumina). Clusters were generated using TruSeq Single-Read Cluster Gen. Kit v3-cBot-HS on an Illumina cBot Cluster Generation Station. After quality control procedures, individual mRNA-Seq or small RNA-Seq libraries were then pooled based on their respective 6-bp index portion of the TruSeq adapters and sequenced at $50 \mathrm{bp} / \mathrm{sequence}$, read using an Illumina HiSeq 3000 sequencer. The barcode combinations were further crosschecked by Illumina Experiment Manager software. Sequence data were checked by assurance (QA) pipeline and initial genome alignment (Alignment). Approximately, 33 million and 5 million reads per sample were generated in mRNA-Seq and miRNA-Seq, respectively. After the sequencing run, demultiplexing with CASAVA was employed to generate the Fastq file for each sample. All sequencing reads were aligned with their reference genome (UCSC mouse genome build mm9) using TopHat2 default settings, and the Bam files from alignment were processed using HTSeq-count to obtain the counts per gene in all samples. Quality control statistical analysis of outliers, intergroup variability, distribution levels, PCA, and hierarchical clustering analysis were performed for statistical validation of the experimental data.

Luciferase reporter assay. The $3^{\prime} \mathrm{UTRs}$ of $A i c d a$ and $\operatorname{Prdm} 1 \mathrm{mRNAs}$ were PCR amplified using Phusion DNA polymerase (New England BioLabs.) from cDNA of B cells stimulated with LPS plus IL-4 and cloned into the pMIR-REPORT miRNA Expression Reporter Vector System (Invitrogen), which allows for analysis of $3^{\prime}$ UTR-mediated regulation of firefly luciferase activity. The mutant (mut) Aicda $3^{\prime}$ UTR containing point mutations in the seed sequences of miR-26a, miR-125a, and miR-155 target sites, and the mut Prdm1 $3^{\prime}$ UTR containing point mutations in the seed sequences of miR-30c, miR-125a, and miR-182 target sites were generated by PCR-based mutagenesis of the Aicda 3'UTR pMIR-REPORT, or the Prdm1 3'UTR pMIR-REPORT vector, respectively ${ }^{33}$. The sequence of constructs was confirmed by two independent sequencing reactions. Reporter constructs were co-transfected with the pRL-TK vector (Promega), which drives constitutive expression of Renilla reniformis luciferase, into mouse $\mathrm{CH} 12 \mathrm{~F} 3 \mathrm{~B}$ cells (a gift from Dr. Tasuku Honjo) by electroporation ( $250 \mathrm{~V}$ and $900 \Omega$ ) with a Gene Pulser II (Bio-Rad). Transfected CH12F3 B cells were then stimulated with CD154 $\left(1 \mathrm{U} \mathrm{ml}^{-1}\right)$, IL-4 $\left(5 \mathrm{ng} \mathrm{ml}^{-1}\right)$, and TGF- $\beta\left(2 \mathrm{ng} \mathrm{ml}^{-1}\right)$ to induce AID expression and CSR to IgA) in the presence nil or butyrate $(500 \mu \mathrm{M})$. The ability of butyrate to repress reporter activity was determined by firefly luciferase activity and normalized to Renilla luciferase activity, according to the manufacturer's instructions, using the Luc-Pair ${ }^{\text {th }}$ DuoLuciferase HS Assay Kit (GeneCopoeia).

Statistical analyses. All statistical analyses were performed using Excel (Microsoft) or GraphPad Prism software. Differences in Ig titers, CSR, and RNA transcript expression were analyzed with Student's paired (in vitro) and unpaired (in vivo) $t$ test assuming two-tailed distributions. Differences in the frequency and spectrum of somatic point mutations were analyzed with $\chi^{2}$ tests. A $p$-value of $<$ 0.05 was considered significant.

Reporting summary. Further information on research design is available in the Nature Research Reporting Summary linked to this article.

\section{Data availability}

The mRNA-sequencing and microRNA-sequencing data have been deposited in NCBI Gene Expression Omnibus (GEO) and is accessible through GEO Series accession number GSE140111. VDJ-sequencing and 16S rRNA gene-sequencing data have been deposited in NCBI Sequence Read Archive (SRA) under BioProject PRJNA588067. The source data underlying Figs. 1a, b, 2c, f, g, 3a-h, 4a, d, g, i, 5h-j, 1, 6c, d, 7a, c, 8a-d, g, h, 9d and 10a and Supplementary Figs. 1a, b, 4a-d, 5, 6c, d, 8a-c, 10a, b, 11a, and 13a are provided as a Source Data file. All the other data supporting the findings of this study are available within the article and its Supplementary Information Files and from the corresponding author upon reasonable request.

Received: 18 November 2018; Accepted: 12 November 2019; Published online: 02 January 2020

\section{References}

1. Rooks, M. G. \& Garrett, W. S. Gut microbiota, metabolites and host immunity. Nat. Rev. Immunol. 16, 341-352 (2016).

2. Honda, K. \& Littman, D. R. The microbiota in adaptive immune homeostasis and disease. Nature 535, 75-84 (2016).

3. Thaiss, C. A., Zmora, N., Levy, M. \& Elinav, E. The microbiome and innate immunity. Nature 535, 65-74 (2016).

4. Blander, J. M., Longman, R. S., Iliev, I. D., Sonnenberg, G. F. \& Artis, D. Regulation of inflammation by microbiota interactions with the host. Nat. Immunol. 18, 851-860 (2017).

5. Lu, C. \& Thompson, C. B. Metabolic regulation of epigenetics. Cell Metab. 16, 9-17 (2012).

6. Li, G., Zan, H., Xu, Z. \& Casali, P. Epigenetics of the antibody response. Trends Immunol. 34, 460-470 (2013).

7. Zan, H. \& Casali, P. Epigenetics of peripheral B-cell differentiation and the antibody response. Front. Immunol. 6, 631 (2015).

8. Shen, T., Sanchez, H. N., Zan, H. \& Casali, P. Genome-wide analysis reveals selective modulation of microRNAs and mRNAs by histone deacetylase inhibitor in B cells induced to undergo class-switch DNA recombination and plasma cell differentiation. Front. Immunol. 6, 627 (2015)

9. Koh, A., De Vadder, F., Kovatcheva-Datchary, P. \& Backhed, F. From dietary fiber to host physiology: short-chain fatty acids as key bacterial metabolites. Cell 165, 1332-1345 (2016) 
10. Brestoff, J. R. \& Artis, D. Commensal bacteria at the interface of host metabolism and the immune system. Nat. Immunol. 14, 676-684 (2013).

11. Singh, N. et al. Blockade of dendritic cell development by bacterial fermentation products butyrate and propionate through a transporter (Slc5a8)-dependent inhibition of histone deacetylases. J. Biol. Chem. 285, 27601-27608 (2010).

12. Kim, M., Qie, Y., Park, J. \& Kim, C. H. Gut microbial metabolites fuel host antibody responses. Cell Host Microbe 20, 202-214 (2016).

13. $\mathrm{Wu}, \mathrm{W}$. et al. Microbiota metabolite short-chain fatty acid acetate promotes intestinal IgA response to microbiota which is mediated by GPR43. Mucosal Immunol. 10, 946-956 (2017).

14. Waldecker, M., Kautenburger, T., Daumann, H., Busch, C. \& Schrenk, D. Inhibition of histone-deacetylase activity by short-chain fatty acids and some polyphenol metabolites formed in the colon. J. Nutr. Biochem. 19, 587-593 (2008).

15. Arpaia, N. et al. Metabolites produced by commensal bacteria promote peripheral regulatory T-cell generation. Nature 504, 451-455 (2013).

16. Alenghat, T. \& Artis, D. Epigenomic regulation of host-microbiota interactions. Trends Immunol. 35, 518-525 (2014).

17. Lopez, C. A., Kingsbury, D. D., Velazquez, E. M. \& Baumler, A. J. Collateral damage: microbiota-derived metabolites and immune function in the antibiotic era. Cell Host Microbe 16, 156-163 (2014).

18. Veldhoen, M. \& Ferreira, C. Influence of nutrient-derived metabolites on lymphocyte immunity. Nat. Med. 21, 709-718 (2015).

19. Furusawa, Y. et al. Commensal microbe-derived butyrate induces the differentiation of colonic regulatory T cells. Nature 504, 446-450 (2013).

20. Trompette, A. et al. Gut microbiota metabolism of dietary fiber influences allergic airway disease and hematopoiesis. Nat. Med. 20, 159-166 (2014).

21. Makki, K., Deehan, E. C., Walter, J. \& Backhed, F. The impact of dietary fiber on gut microbiota in host health and disease. Cell Host Microbe 23, 705-715 (2018).

22. Wang, L., de Zoeten, E. F., Greene, M. I. \& Hancock, W. W. Immunomodulatory effects of deacetylase inhibitors: therapeutic targeting of FOXP3 + regulatory T cells. Nat. Rev. Drug Discov. 8, 969-981 (2009).

23. Hedrich, C. M. \& Tsokos, G. C. Epigenetic mechanisms in systemic lupus erythematosus and other autoimmune diseases. Trends Mol. Med. 17, 714-724 (2011).

24. Kaisar, M. M. M., Pelgrom, L. R., van der Ham, A. J., Yazdanbakhsh, M. \& Everts, B. Butyrate conditions human dendritic cells to prime type 1 regulatory $\mathrm{T}$ cells via both histone deacetylase inhibition and $\mathrm{G}$ proteincoupled receptor 109 A signaling. Front. Immunol. 8, 1429 (2017).

25. Akimova, T. et al. Histone/protein deacetylase inhibitors increase suppressive functions of human FOXP3 + Tregs. Clin. Immunol. 136, 348-363 (2010).

26. Chang, P. V., Hao, L., Offermanns, S. \& Medzhitov, R. The microbial metabolite butyrate regulates intestinal macrophage function via histone deacetylase inhibition. Proc. Natl Acad. Sci. USA 111, 2247-2252 (2014).

27. Tan, J. et al. Dietary fiber and bacterial SCFA enhance oral tolerance and protect against food allergy through diverse cellular pathways. Cell Rep. 15, 2809-2824 (2016).

28. Kim, S. H., Cho, B. H., Kiyono, H. \& Jang, Y. S. Microbiota-derived butyrate suppresses group 3 innate lymphoid cells in terminal ileal Peyer's patches. Sci. Rep. 7, 3980 (2017).

29. Thio, C. L., Chi, P. Y., Lai, A. C. \& Chang, Y. J. Regulation of type 2 innate lymphoid cell-dependent airway hyperreactivity by butyrate. J. Allergy Clin. Immunol. 142, 1867-1883 (2018).

30. Kabat, A. M., Srinivasan, N. \& Maloy, K. J. Modulation of immune development and function by intestinal microbiota. Trends Immunol. 35, 507-517 (2014).

31. Zeng, H. \& Chi, H. Metabolic control of regulatory $\mathrm{T}$ cell development and function. Trends Immunol. 36, 3-12 (2015).

32. Asarat, M., Apostolopoulos, V., Vasiljevic, T. \& Donkor, O. Short-chain fatty acids regulate cytokines and Th17/Treg cells in human peripheral blood mononuclear cells in vitro. Immunol. Invest. 45, 205-222 (2016).

33. White, C. A. et al. Histone deacetylase inhibitors upregulate B cell microRNAs that silence AID and Blimp-1 expression for epigenetic modulation of antibody and autoantibody responses. J. Immunol. 193, 5933-5950 (2014).

34. Waibel, M. et al. Manipulation of B-cell responses with histone deacetylase inhibitors. Nat. Commun. 6, 6838 (2015).

35. Huberfeld, G. \& Vecht, C. J. Seizures and gliomas-towards a single therapeutic approach. Nat. Rev. Neurol. 12, 204-216 (2016).

36. Lindemann, R. K. et al. Analysis of the apoptotic and therapeutic activities of histone deacetylase inhibitors by using a mouse model of B cell lymphoma. Proc. Natl Acad. Sci. USA 104, 8071-8076 (2007).

37. Chesi, M. et al. Drug response in a genetically engineered mouse model of multiple myeloma is predictive of clinical efficacy. Blood 120, 376-385 (2012).

38. Biermann, J., Boyle, J., Pielen, A. \& Lagreze, W. A. Histone deacetylase inhibitors sodium butyrate and valproic acid delay spontaneous cell death in purified rat retinal ganglion cells. Mol. Vis. 17, 395-403 (2011).
39. Hancock, W. W., Akimova, T., Beier, U. H., Liu, Y. \& Wang, L. HDAC inhibitor therapy in autoimmunity and transplantation. Ann. Rheum. Dis. 71 (Suppl 2), i46-i54 (2012).

40. Belkaid, Y. \& Harrison, O. J. Homeostatic immunity and the microbiota. Immunity 46, 562-576 (2017).

41. Thorburn, A. N. et al. Evidence that asthma is a developmental origin disease influenced by maternal diet and bacterial metabolites. Nat. Commun. 6, 7320 (2015).

42. Mombaerts, P. et al. Mutations in T-cell antigen receptor genes alpha and beta block thymocyte development at different stages. Nature 360, 225-231 (1992).

43. Shultz, L. D. et al. Human lymphoid and myeloid cell development in NOD/ LtSz-scid IL2R gamma null mice engrafted with mobilized human hemopoietic stem cells. J. Immunol. 174, 6477-6489 (2005).

44. Donohoe, D. R. et al. The microbiome and butyrate regulate energy metabolism and autophagy in the mammalian colon. Cell Metab. 13, 517-526 (2011).

45. Cait, A. et al. Microbiome-driven allergic lung inflammation is ameliorated by short-chain fatty acids. Mucosal Immunol. 11, 785-795 (2018).

46. Sun, M. et al. Microbiota-derived short-chain fatty acids promote Th1 cell IL10 production to maintain intestinal homeostasis. Nat. Commun. 9, 3555 (2018).

47. Takai, A. et al. Targeting activation-induced cytidine deaminase prevents colon cancer development despite persistent colonic inflammation. Oncogene 31, 1733-1742 (2012).

48. Ganapathy, V., Thangaraju, M., Prasad, P. D., Martin, P. M. \& Singh, N. Transporters and receptors for short-chain fatty acids as the molecular link between colonic bacteria and the host. Curr. Opin. Pharmacol. 13, 869-874 (2013).

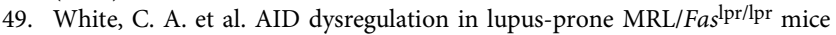
increases class switch DNA recombination and promotes interchromosomal c-Myc/IgH loci translocations: modulation by HoxC4. Autoimmunity 44, 585-598 (2011)

50. Bantscheff, M. et al. Chemoproteomics profiling of HDAC inhibitors reveals selective targeting of HDAC complexes. Nat. Biotechnol. 29, 255-265 (2011).

51. Thangaraju, M., Carswell, K. N., Prasad, P. D. \& Ganapathy, V. Colon cancer cells maintain low levels of pyruvate to avoid cell death caused by inhibition of HDAC1/HDAC3. Biochem. J. 417, 379-389 (2009).

52. Seto, E. \& Yoshida, M. Erasers of histone acetylation: the histone deacetylase enzymes. Cold Spring Harb. Perspect. Biol. 6, a018713 (2014).

53. Bieliauskas, A. V. \& Pflum, M. K. Isoform-selective histone deacetylase inhibitors. Chem. Soc. Rev. 37, 1402-1413 (2008).

54. Tang, X. et al. Acetylation of Drosha on the N-terminus inhibits its degradation by ubiquitination. PLoS ONE 8, e72503 (2013).

55. Fernandes, J., Su, W., Rahat-Rozenbloom, S., Wolever, T. M. \& Comelli, E. M. Adiposity, gut microbiota and faecal short chain fatty acids are linked in adult humans. Nutr. Diabetes 4, e121 (2014).

56. Ley, R. E., Turnbaugh, P. J., Klein, S. \& Gordon, J. I. Microbial ecology: human gut microbes associated with obesity. Nature 444, 1022-1023 (2006).

57. Rahat-Rozenbloom, S., Fernandes, J., Gloor, G. B. \& Wolever, T. M. Evidence for greater production of colonic short-chain fatty acids in overweight than lean humans. Int. J. Obes. 38, 1525-1531 (2014).

58. Sheridan, P. A. et al. Obesity is associated with impaired immune response to influenza vaccination in humans. Int. J. Obes. 36, 1072-1077 (2012).

59. Wesemann, D. R. Microbes and B cell development. Adv. Immunol. 125, 155-178 (2015).

60. Hooper, L. V. \& Macpherson, A. J. Immune adaptations that maintain homeostasis with the intestinal microbiota. Nat. Rev. Immunol. 10, 159-169 (2010).

61. Bunker, J. J. et al. Innate and adaptive humoral responses coat distinct commensal bacteria with immunoglobulin A. Immunity 43, 541-553 (2015).

62. Egorin, M. J., Yuan, Z. M., Sentz, D. L., Plaisance, K. \& Eiseman, J. L. Plasma pharmacokinetics of butyrate after intravenous administration of sodium butyrate or oral administration of tributyrin or sodium butyrate to mice and rats. Cancer Chemother. Pharmacol. 43, 445-453 (1999).

63. Park, S. R. et al. HoxC4 binds to the promoter of the cytidine deaminase AID gene to induce AID expression, class-switch DNA recombination and somatic hypermutation. Nat. Immunol. 10, 540-550 (2009).

64. Zan, H. et al. Rad52 competes with Ku70/Ku86 for binding to S-region DSB ends to modulate antibody class-switch DNA recombination. Nat. Commun. 8, 14244 (2017).

65. Zan, H. et al. Rev1 recruits Ung to switch regions and enhances dU glycosylation for immunoglobulin class switch DNA recombination. Cell Rep. 2, 1220-1232 (2012).

66. Lam, T. et al. Small molecule inhibition of Rab7 impairs B cell class switching and plasma cell survival to dampen the autoantibody response in murine lupus. J. Immunol. 197, 3792-3805 (2016). 
67. Wang, Q., Garrity, G. M., Tiedje, J. M. \& Cole, J. R. Naive bayesian classifier for rapid assignment of rRNA sequences into the new bacterial taxonomy. Appl. Environ. Microbiol. 73, 5261-5267 (2007).

\section{Acknowledgements}

We are grateful to Daniel P. Chupp, Carlos Rivera, Yijiang Xu, Anusha Vasudev, and Cassidy C. Daw for helping with some experiments. We thank Dr. Zhao Lai (UT Health Genome Sequencing Facility) for high-throughput sequencing, Yi Zou and Dr. Yidong Chen for bioinformatics analysis. We also thank Dr. Xiaoli Gao (UT Health Mass Spectrometry Laboratory) for analysis of SCFA concentrations, Shellye Lampkin (UT Health Histology \& Immunohistochemistry Laboratory) and the UT Health Flow Cytometry core. The UT Health Genome Sequencing Facility/Bioinformatics is supported by NIH-NCI P30 CA054174 (Cancer Center at UT Health San Antonio), NIH Shared Instrument S10 grant 1S10OD021805-01, CPRIT Core Facility Award RP160732 and NIH IIMS/CTSA grant UL1 TR002645. The UT Health Flow Cytometry core is supported by NIH-NCI P30 CA054174-20 and NIH IIMS/CTSA grant UL1 TR001120. This work was supported by NIH grants R01 AI105813, R01 AI079705, T32 AI138944, and Lupus Research Alliance TIL grant LRA641363 to P.C.

\section{Author contributions}

H.N.S. and J.B.M. performed experiments, analyzed the data, and helped write the paper; H.G., T.S., J.L.I. and J.R.T. performed experiments; T.L. analyzed sequencing data; H.Z. planned the study, designed and performed experiments, analyzed and organized the data, and wrote the paper; P.C. planned the study, designed the experiments, coordinated and supervised the work, analyzed and organized the data, and wrote the paper.

\section{Competing interests}

The authors declare no competing interests.

\section{Additional information}

Supplementary information is available for this paper at https://doi.org/10.1038/s41467019-13603-6.

Correspondence and requests for materials should be addressed to H.Z. or P.C.

Peer review information Nature Communications thanks the anonymous reviewers for their contributions to the peer review of this work.

Reprints and permission information is available at http://www.nature.com/reprints

Publisher's note Springer Nature remains neutral with regard to jurisdictional claims in published maps and institutional affiliations.

(c) Open Access This article is licensed under a Creative Commons Attribution 4.0 International License, which permits use, sharing, adaptation, distribution and reproduction in any medium or format, as long as you give appropriate credit to the original author(s) and the source, provide a link to the Creative Commons license, and indicate if changes were made. The images or other third party material in this article are included in the article's Creative Commons license, unless indicated otherwise in a credit line to the material. If material is not included in the article's Creative Commons license and your intended use is not permitted by statutory regulation or exceeds the permitted use, you will need to obtain permission directly from the copyright holder. To view a copy of this license, visit http://creativecommons.org/ licenses/by/4.0/.

(C) The Author(s) 2020 